\title{
Normalization of magnesium deficiency attenuated mechanical allodynia, depressive-like behaviors, and memory deficits associated with cyclophosphamide- induced cystitis by inhibiting TNF-a/NF-KB signaling in female rats
}

Jia-Liang Chen ${ }^{1+}$, Xin Zhou ${ }^{2 \dagger}$, Bo-Long Liu ${ }^{1+}$, Xu-Hong Wei ${ }^{2}$, Hong-Lu Ding ${ }^{1}$, Zhi-Jun Lin ${ }^{1}$, Hai-Lun Zhan ${ }^{1}$, Fei Yang ${ }^{1}$, Wen-Biao Li ${ }^{1}$, Jun-Cong Xie ${ }^{1}$, Min-Zhi Su ${ }^{4}$, Xian-Guo Liü ${ }^{2,3^{*}}$ and Xiang-Fu Zhou ${ }^{1 *}$

\begin{abstract}
Background: Bladder-related pain symptoms in patients with bladder pain syndrome/interstitial cystitis (BPS/IC) are often accompanied by depression and memory deficits. Magnesium deficiency contributes to neuroinflammation and is associated with pain, depression, and memory deficits. Neuroinflammation is involved in the mechanical allodynia of cyclophosphamide (CYP)-induced cystitis. Magnesium-L-Threonate (L-TAMS) supplementation can attenuate neuroinflammation. This study aimed to determine whether and how L-TAMS influences mechanical allodynia and accompanying depressive symptoms and memory deficits in CYP-induced cystitis.

Methods: Injection of CYP (50 mg/kg, intraperitoneally, every 3 days for 3 doses) was used to establish a rat model of BPS/IC. L-TAMS was administered in drinking water $\left(604 \mathrm{mg} \cdot \mathrm{kg}^{-1} \cdot \mathrm{day}^{-1}\right)$. Mechanical allodynia in the lower abdomen was assessed with von Frey filaments using the up-down method. Forced swim test (FST) and sucrose preference test (SPT) were used to measure depressive-like behaviors. Novel object recognition test (NORT) was used to detect short-term memory function. Concentrations of $\mathrm{Mg}^{2+}$ in serum and cerebrospinal fluid (CSF) were measured by calmagite chronometry. Western blot and immunofluorescence staining measured the expression of tumor necrosis factor-a/nuclear factor-KB (TNF-a/NF-KB), interleukin-1 $\beta$ (IL-1B), and N-methyl-D-aspartate receptor type 2B subunit (NR2B) of the N-methyl-D-aspartate receptor in the L6-S1 spinal dorsal horn (SDH) and hippocampus.
\end{abstract}

\footnotetext{
* Correspondence: liuxg@mail.sysu.edu.cn; zhouxfu@mail.sysu.edu.cn

${ }^{\dagger}$ Jia-Liang Chen, Xin Zhou and Bo-Long Liu contributed equally to this work.

${ }^{2}$ Pain Research Center and Department of Physiology, Zhongshan School of

Medicine, Sun Yat-sen University, 74 Zhongshan Rd. 2, Guangzhou 510080,

China

${ }^{1}$ Department of Urology, The Third Affiliated Hospital of Sun Yat-sen

University, 600 W Tianhe Rd, Guangzhou 510630, China

Full list of author information is available at the end of the article
}

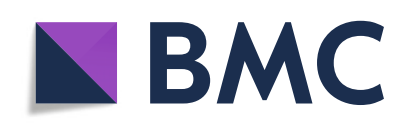

(- The Author(s). 2021, corrected publication 2021. Open Access This article is licensed under a Creative Commons Attribution 4.0 International License, which permits use, sharing, adaptation, distribution and reproduction in any medium or format, as long as you give appropriate credit to the original author(s) and the source, provide a link to the Creative Commons licence, and indicate if changes were made. The images or other third party material in this article are included in the article's Creative Commons licence, unless indicated otherwise in a credit line to the material. If material is not included in the article's Creative Commons licence and your intended use is not permitted by statutory regulation or exceeds the permitted use, you will need to obtain permission directly from the copyright holder. To view a copy of this licence, visit http://creativecommons.org/ licenses/by/4.0/. The Creative Commons Public Domain Dedication waiver (http://creativecommons.org/publicdomain/zero/1. 0/) applies to the data made available in this article, unless otherwise stated in a credit line to the data. 
Results: Free $\mathrm{Mg}^{2+}$ was reduced in the serum and CSF of the CYP-induced cystitis rats on days 8, 12, and 20 after the first CYP injection. Magnesium deficiency in the serum and CSF correlated with the mechanical withdrawal threshold, depressive-like behaviors, and short-term memory deficits (STMD). Oral application of L-TAMS prevented magnesium deficiency and attenuated mechanical allodynia $(n=14)$ and normalized depressive-like behaviors $(n=10)$ and STMD $(n=10)$. The upregulation of TNF- $/$ /NF-KB signaling and IL-1 $\beta$ in the L6-S1 SDH or hippocampus was reversed by LTAMS. The change in NR2B expression in the SDH and hippocampus in the cystitis model was normalized by L-TAMS.

Conclusions: Normalization of magnesium deficiency by L-TAMS attenuated mechanical allodynia, depressive-like behaviors, and STMD in the CYP-induced cystitis model via inhibition of TNF-a/NF-KB signaling and normalization of NR2B expression. Our study provides evidence that L-TAMS may have therapeutic value for treating pain and comorbid depression or memory deficits in BPS/IC patients.

Keywords: Bladder pain syndrome, Cystitis, Neuroinflammation, Depression, Memory dysfunction

\section{Background}

Depression and memory deficits are two serious comorbidities of chronic pain. A community population-based research study revealed that approximately one third of participants with chronic pain also had comorbid depression [1]. About two thirds of patients with chronic pain also have memory dysfunction [2]. Bladder pain syndrome/ interstitial cystitis (BPS/IC) is a chronic condition where urinary bladder-related pain is a symptom that impacts a patient's life. Population-based studies have shown that the female-to-male ratio ranges from 5:1 [3] to 10:1 [4], and most clinical studies include women only since confounding diagnoses are common in men with chronic prostatitis [5]. Additionally, depression and memory problems often accompany and amplify the symptoms of BPS/IC [6]. A previous study revealed that about one third of these patients have depressive disorders [7]. More female patients suffer from depression than males [8]. A population-based study also showed that patients with BPS/IC were more likely to have memory problems than healthy people [9], and patients with BPS/IC with depression report increased pain scores [7]. However, there are limited satisfying treatment options presently available to improve both the pain symptoms and the comorbidities of BPS/IC. Moreover, the mechanisms underlying the comorbidity of bladder-related pain and depression/memory dysfunction in BPS/IC are not clearly identified. The clarification of such mechanisms is complex, but the exploration of factors that can link the comorbidities is easier and also of great clinical value.

It has been suggested that magnesium deficiency is associated with neuropathic pain [10] and induces nociception sensitization in normal animals $[11,12]$. Moreover, magnesium deficiency is also correlated with the depressive symptoms induced by fibromyalgia [13] (a pain syndrome often accompanied with BPS/IC) and the impaired memory function associated with neuropathic pain [14]. However, whether magnesium deficiency is associated with bladderrelated pain and comorbid depression or memory dysfunction is still unknown.
Inflammatory mechanisms, especially neuroinflammation, are believed to play an important role in the development of pain, depression, and memory deficits [15-17]. Our previous work demonstrated that neuroinflammation participates in the initiation and maintenance of mechanical allodynia in cyclophosphamide (CYP)-induced cystitis [18, 19]. Moreover, intrathecal (i.t.) injection of IL-1ra (interleukin-1 receptor antagonist) significantly attenuated the mechanical allodynia induced by CYP-induced cystitis [19]. However, whether neuroinflammation is also associated with depression or memory deficits in the cystitis model and whether inhibition of neuroinflammation influences these two comorbidities are still unknown.

Taken together, magnesium deficiency and neuroinflammation are two underlying therapeutic targets to treat pain and comorbid depression and memory deficits. Interestingly, it has been reported that magnesium deficiency potentiates a generalized inflammatory state [20] and also evokes neuroinflammation leading to depressive-like behavior [21]. Supplementation of magnesium may inhibit such an inflammatory response, especially the neuroinflammatory component. As a novel magnesium compound, magnesium-L-Threonate (LTAMS) has been found to be able to infiltrate through the blood-brain barrier and elevate brain magnesium levels following oral application [22]. Previous research showed that L-TAMS could improve memory function in Alzheimer's disease (AD) through inhibition of neuroinflammation [23]. Additionally, L-TAMS was able to inhibit neuroinflammation, leading to attenuation of neuropathic pain as well as neuropathic pain-associated memory deficits $[14,24]$. However, no study has shown whether and how L-TAMS influences bladder-related pain and the accompanying depressive symptoms and memory deficits in BPS/IC.

Based on the above evidence, we hypothesize that LTAMS could have a therapeutic effect on mechanical allodynia and on comorbid depression and memory deficits in the CYP-induced cystitis model. This study aimed 
to investigate whether and how oral application of LTAMS could attenuate the symptoms described above in the CYP-induced cystitis model.

\section{Methods}

\section{Animals}

Female Sprague Dawley rats (200-220 g) were obtained from the Institute of Experimental Animals of Sun Yatsen University, Guangzhou, China. The animals were housed in a temperature- and humidity-controlled room $\left(24 \pm 1{ }^{\circ} \mathrm{C}\right)$ under a $12 / 12$-h light/dark cycle (06:00-18:00 h). Animals had access to food and water ad libitum. All experimental procedures were approved by the Animal Care Committee of Sun Yat-sen University and conducted in accordance with the guidelines of the National Institutes of Health on animal care and ethical guidelines.

\section{Drug administration}

CYP was used to establish the cystitis model as previously described [18]. Briefly, CYP (50 mg/kg; Sigma, St Louis, $\mathrm{MO}$ ) was intraperitoneally (i.p.) injected every 3 days for 3 doses. Oral application of L-TAMS (Neurocentria Inc., USA) was used as a method of supplementing magnesium. L-TAMS was administered in drinking water $(604 \mathrm{mg} \cdot \mathrm{kg}$ ${ }^{-1}$.day ${ }^{-1}$ ) [22, 24] along with $50 \mathrm{mg} \cdot \mathrm{kg}^{-1} \cdot$ day $^{-1}$ of elemental magnesium over the course of the study. L-TAMS was applied over two different time periods as shown in Fig. $1 \mathrm{~b}$ and Fig. 3a, b: one was initiated 3 days prior to the first CYP dose while the other was initiated 1 day post the last CYP injection.

\section{Experimental design}

The flowchart for experimental design is provided in Fig. 1 , and the number of animals used in each test was outlined in Supplemental Table 1. We designed three experimental parts for our present study. In part I, four animal groups were included: the Veh group as a control that was saline injected i.p., while the other three groups, CYP d8, CYP d12, and CYP d20, were CYP-treated and anesthetized for western blot sample harvest on days 8 , 12 , and 20 , respectively, after the first CYP injection. The magnesium concentration changes were evaluated in serum and cerebrospinal fluid (CSF) at these three time points. In addition, the correlation between $\mathrm{Mg}^{2+}$ and bladder-related pain or comorbidities was also assessed. Moreover, the expression changes in TNF- $\alpha /$ NF- $\mathrm{KB}$ and related factors, including interleukin-1beta (IL-1 $\beta$ ) and $N$-methyl-D-aspartate (NMDA) receptor type 2B (NR2B), were also assessed using western blot analysis.

Part II of the study helped us to understand whether and how magnesium deficiency influences bladderrelated pain and comorbidities, as we performed behavioral evaluation to explore whether normalization of magnesium deficiency with L-TAMS can attenuate bladder-related pain and comorbid depressive symptoms (d20), or memory deficits (d18) in the CYP-induced cystitis rat model. In this part, four animal groups were included: the Veh group with drinking water, the LTAMS group having normal animals with L-TAMS, the CYP group with drinking water, and the CYP + LTAMS group having cystitis animals with L-TAMS. To avoid mutual influence among the different behavioral tests, each group only received one behavioral test and then anesthetized on day 20 for $\mathrm{Mg}^{2+}$ measurements. Additionally, on day 20, tissue samples for western blot analysis and immunofluorescence to measure the expression change of TNF- $\alpha / N F-k B$, IL- $1 \beta$, and NR2B were harvested from animals that received the von Frey test.

Last, we set up part III of the study to verify whether inhibition of NF- $\mathrm{KB}$ signaling with pyrrolidinedithiocarbamate ammonium (PDTC) can directly alleviate bladder-related pain as well as the comorbid depressivelike symptoms and memory deficits in the CYP-induced cystitis animal model. Four groups were included in this part: the Veh group with DMSO, the PDTC group having normal animals with PDTC, the CYP group, and the CYP + PDTC group having cystitis animals with PDTC.

\section{Intrathecal injection}

Intrathecal injection (i.t.) was performed as described previously [25]. Under anesthesia, a 25-G needle connected to a $25-\mu l$ Hamilton syringe was inserted percutaneously into the vertebral canal between L5 and L6. A tail-flick reaction denoted a successful puncture. A rat was injected i.t. with $20 \mu \mathrm{l}$ of $1 \%$ Chicago sky blue (C8678, Sigma-Aldrich) to determine whether the drug injected i.t. was able to reach the L6-S1 spinal cord level. After that, a dose of $200 \mathrm{ng}$ [26] of the NF-kB signaling inhibitor PDTC was injected i.t. for 3 consecutive days after the last CYP injection.

\section{Measurement of mechanical withdrawal threshold}

Since bladder-related pain is difficult to assess directly, measurement of the lower abdominal withdrawal threshold was used as a substitute for assessment of bladderrelated pain [27]. The up-down method, as described previously [28], and a series of von Frey filaments (rated at $0.4,0.6,1,2,4,6,8,15 \mathrm{~g}$ ) were used to measure evoked pain in the lower abdomen, the area of referred pain associated with vesical pathologies. Animals were acclimatized to the chamber environment for $30 \mathrm{~min}$ every day for 2 days before testing, and those with an abnormal basic pain threshold were excluded. Different lower abdominal areas were stimulated to avoid desensitization. The 2-g stimulus in the middle of the series was applied first. Each stimulus consisted of a $6-$ 


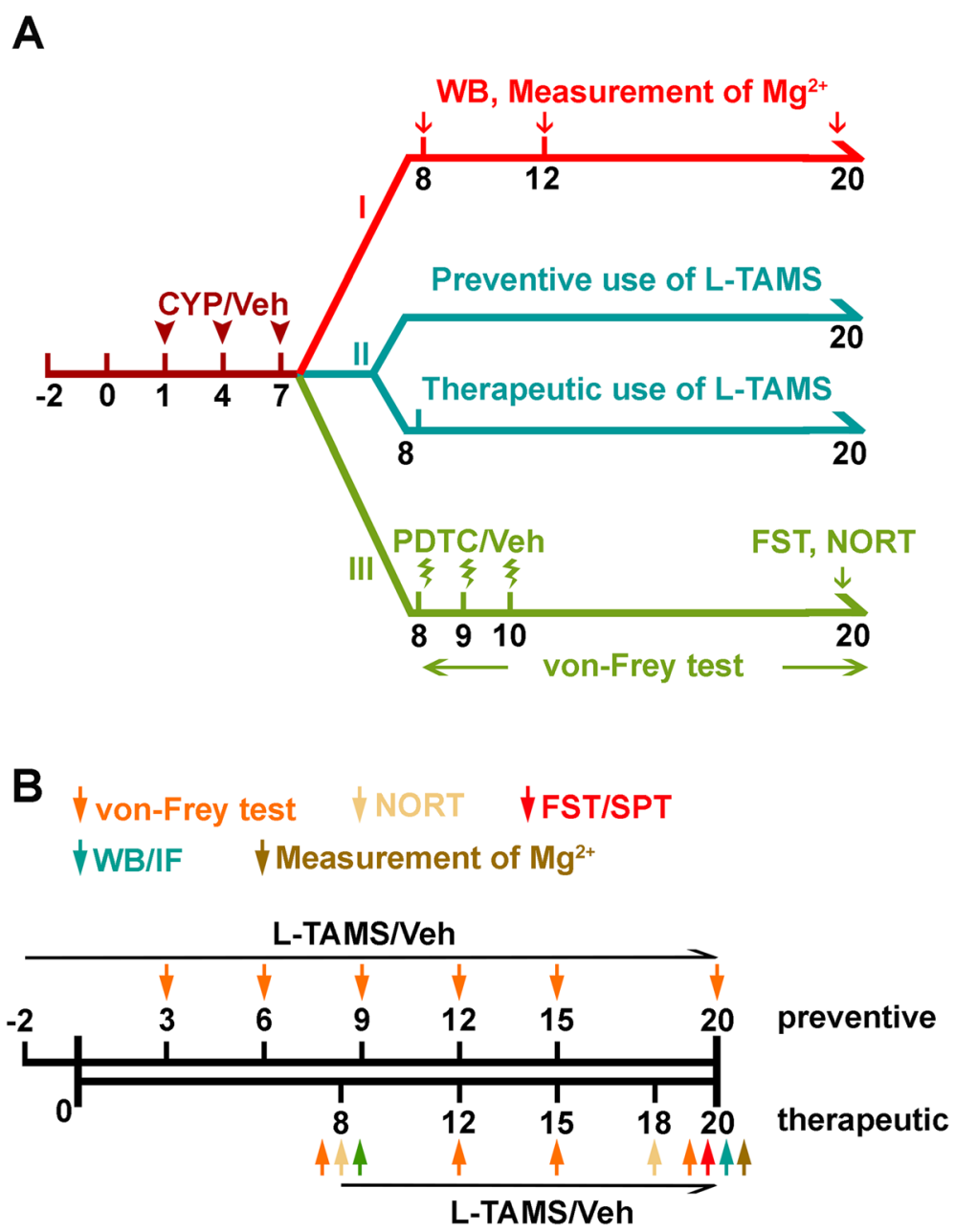

Fig. 1 Flowchart of the experimental procedure. a The study consisted of three parts. In part I, western blot analyses were performed at the three time points, day 8, day 12, and day 20, to determine the expression level of TNF-a/NF-KB, IL-1 $\beta$, and NR2B in CYP-induced cystitis animals. The concentration of $\mathrm{Mg}^{2+}$ was also measured at the three time points. In part II, after treatment with L-TAMS, behavioral tests and molecular experiments were performed to investigate the effect of L-TAMS in the CYP-treated animals. The details in part II were shown in $\mathbf{b}$. Additionally, in part III, the effect of inhibiting NF-KB signaling was determined by behavioral tests

8-s application of the von Frey filament to the lower abdominal region in at least 5-min intervals. A stronger or weaker filament was applied after a negative or positive response, respectively, was elicited. "Licking behavior" and "freezing behavior" were considered positive responses.

\section{Behavioral experiments}

Forced swim test (FST) was used to detect depressivelike behavior as previously described [29] with slight modifications. Rats were placed individually in a transparent glass cylinder tank $(50 \mathrm{~cm}$ height $\times 30 \mathrm{~cm}$ in diameter) filled with water to $45 \mathrm{~cm}$ depth at $22-25^{\circ} \mathrm{C}$. The tank was thoroughly cleaned before testing, and the water was changed after each test. The day prior to the test, rats were placed into the tank and swam for $15 \mathrm{~min}$. On the test day, swimming behavior was assessed for 6 min and the immobility time (floating and treading water just enough to keep the head above water) was recorded during the last $4 \mathrm{~min}$.

Sucrose preference test (SPT) was also carried out to determine depressive-like behaviors. The test was performed as previously described [30]. Briefly, rats were singly housed and trained to drink $2 \%$ sucrose solution in place of water for 2 days. After that, rats were deprived of water for $24 \mathrm{~h}$ and then underwent a 2 -h test, during which they were exposed to one bottle of water and one bottle of $2 \%$ sucrose solution. Additionally, during the 2-h test, the positions of the two bottles were switched at the 1-h time point. Total consumption of each fluid was then measured, and the sucrose consumption ratio was calculated as a ratio of the total consumption of sucrose over the total consumption of both water and sucrose.

Novel object recognition test (NORT) was used to determine short-term memory ability, as previously described 
[15]. Before the test, each rat was acclimated to the opaque box $(60 \times 60 \times 40 \mathrm{~cm})$ for $10 \mathrm{~min}$ each day for two consecutive days. The test was divided into two sections. In the sample phase, each rat was exposed to two different objects in the box for $5 \mathrm{~min}$. After a 10-min retention interval, the less explored object of the two was replaced by a new one and the rat was placed back in the box and exposed to two objects (the familiar one and a novel one) for a further 5-min "acquisition phase." An experimenter blinded to the identity of the tested rats then measured the time spent exploring each object. The recognition index reflecting the short-term memory ability was set as the percent time spent exploring the novel object.

\section{Measurement of extracellular free magnesium}

The calmagite chronometry method [31] was used to measure the concentration of free $\mathrm{Mg}^{2+}$ in serum and CSF of rats. The blood samples were collected from the orbital sinus and then centrifuged at $2000 \mathrm{rpm}$ for $10 \mathrm{~min}$ to isolate serum, and CSF was collected from the cisterna magna.

\section{Western blot analysis}

We used a modified western blot protocol [32] in our present study. Rats were anesthetized with sodium pentobarbital $(50 \mathrm{mg} / \mathrm{kg}$, i.p.). The L6-S1 spinal dorsal horn $(\mathrm{SDH})$ and hippocampus were quickly harvested, and the supernatant was collected and then frozen at $80^{\circ} \mathrm{C}$ after the tissue samples were mechanically homogenized and centrifuged. Samples were homogenized in RIPA lysis buffer containing proteinase and phosphatase inhibitors. The bicinchoninic acid method was used to measure the protein concentration of the supernatant. Proteins in the supernatant were separated by sodium dodecyl sulfate-polyacrylamide gel electrophoresis and then transferred onto polyvinylidene fluoride membranes (Millipore, Billerica, MA, USA). The membranes were blocked in $5 \%$ bovine serum albumin solution for 60-90 min at $37^{\circ} \mathrm{C}$. After blocking, the blots were incubated with primary antibody (reference/RRID shown in Supplemental Table 2) for TNF- $\alpha$ (1:1000; Bioworld Technology, Inc., Louis Park, MN, USA), phospho-p65 (p-p65, Ser311, 1:1000; Affinity Biosciences, OH, USA), p65 (1:1000; Abcam, Cambridge, UK), IL-1ß (1:2500; Abcam), NR2B (1:1000; Abcam), and $\beta$-actin (1:1000; Cell Signaling Technology, Danvers, MA) overnight at $4{ }^{\circ} \mathrm{C}$. Secondary antibodies conjugated with horseradish peroxidase (1:10,000; KPL, SeraCare, Milford, MA, USA) were applied, and the membrane was incubated for $1 \mathrm{~h}$. Immune complexes were detected with an enhanced chemiluminescence liquid (Millipore). A computerassisted imaging analysis system (Image); National Institutes of Health, Bethesda, MD, USA) was used to quantify the band intensities.

\section{Immunofluorescence}

Immunofluorescence was performed as described in a previous study [33]. Under sodium pentobarbital anesthesia (50 mg/kg, i.p.), rats were perfused with $4 \%$ paraformaldehyde through the ascending aorta. The L6-S1 spinal cord section and brain were removed and post-fixed in paraformaldehyde for $30 \mathrm{~min}$. The spinal cord and brain were then transferred to $30 \%$ sucrose for dehydration at $4{ }^{\circ} \mathrm{C}$. Tissues underwent sectioning (25- $\mu \mathrm{m}$ thickness) and were processed for immunofluorescence staining. Sections were blocked for $1 \mathrm{~h}$ and then incubated with primary antibodies against TNF- $\alpha$ (1:200; Bioworld), $p$-p65 (1:100; Affinity), IL$1 \beta$ (1:500; Abcam), neuronal nuclei (NeuN, 1:200; Millipore), glial fibrillary acidic protein (GFAP, 1:400; CST), and CD11b (OX-42, 1:400; Abcam) overnight at $4{ }^{\circ} \mathrm{C}$. After incubation, the sections were incubated in Cy3 or Alexa-488 (Jackson Laboratories, Bar Harbor, ME, USA) conjugated secondary antibodies for $1 \mathrm{~h}$ at room temperature. A Leica fluorescence microscope (Leica DFC350 FX camera; Wetzlar, Germany) was used to measure and image the stained section. To quantify TNF- $\alpha, p$-p65, and IL-1 $\beta$ expression in the L6-S1 SDH and hippocampus, the fluorescence intensity of each area was analyzed with ImageJ software. To verify the specificity of the antibodies used in our study, immunostaining was also performed in the same way but without primary antibodies. As shown in Supplemental Figure 1 , the specificity of the antibody for $p$-p65 (S311) was identified by pre-absorption with blocking peptide.

\section{Statistical analysis}

All data are expressed as mean \pm standard error of the mean (SEM). SPSS 21.0 (SPSS, Inc., Chicago, IL, USA) was used to perform data analyses. The FST, SPT, NORT (Fig. 7c), western blot, immunofluorescence, and $\mathrm{Mg}^{2+}$ data were analyzed with a one-way analysis of variance (ANOVA) followed by the Tukey post hoc test for comparisons of more than three groups. For the mechanical withdrawal threshold and NORT (Fig. 3e), the data were statistically analyzed using a repeated-measures two-way ANOVA followed by a Tukey post hoc test. The ShapiroWilk test was used to verify normal distribution of the data before each ANOVA test. Linear regression analysis was performed, and the correlation coefficients were calculated to determine the relationship between $\mathrm{Mg}^{2+}$ and mechanical withdrawal threshold or floating time or recognition index. Differences with $P<0.05$ were considered statistically significant.

\section{Results}

Magnesium deficiency in serum and CSF of the CYPinduced cystitis model was reversed by L-TAMS

As shown in Fig. $2 \mathrm{a}-\mathrm{d}, \mathrm{Mg}^{2+}$ concentrations in both the serum and CSF were reduced at the three time points, day 8 , day 12 , and day 20 , after the first CYP injection. 


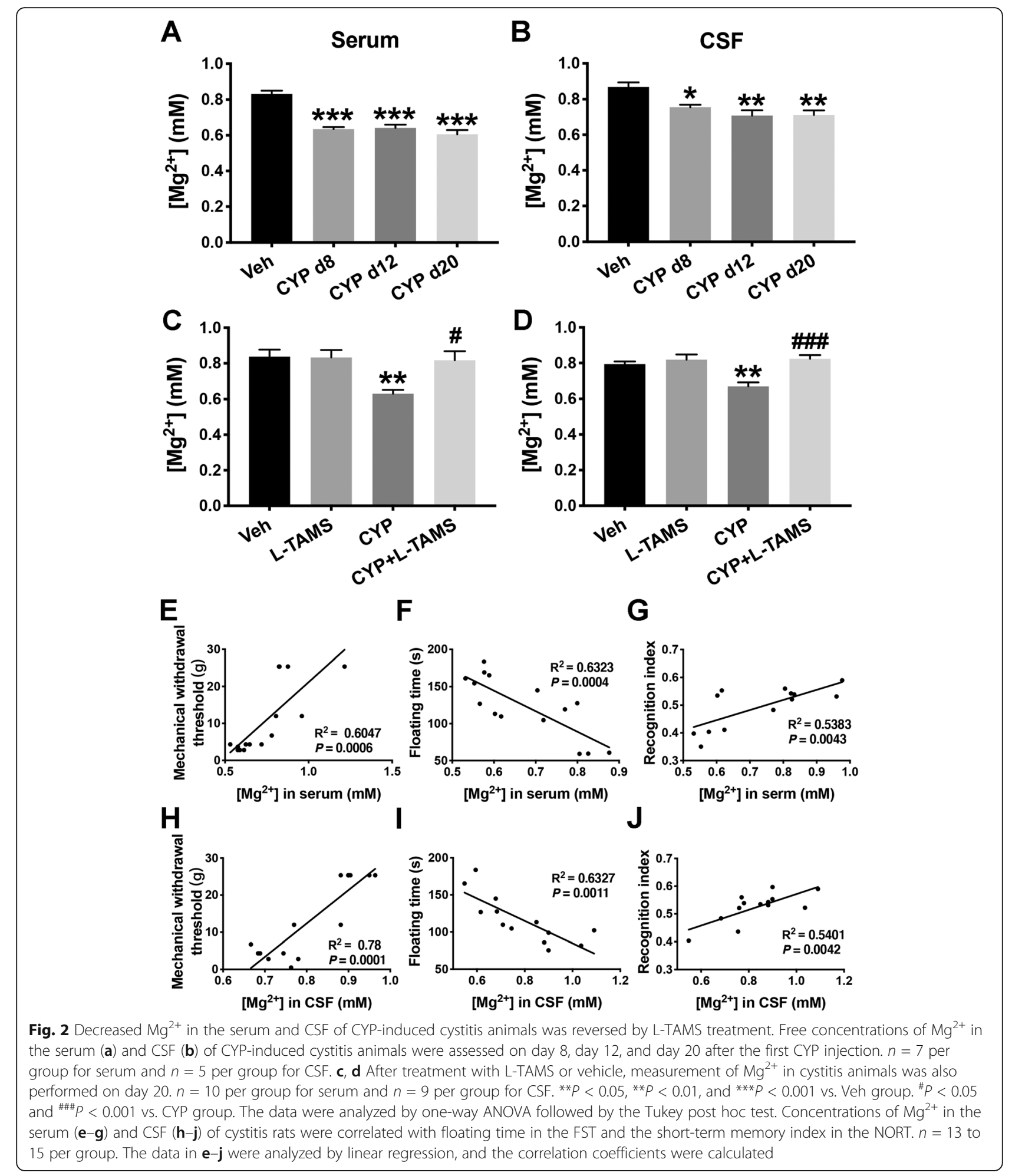

Furthermore, oral application of L-TAMS reversed the reduction in $\mathrm{Mg}^{2+}$ concentrations and returned them to basal levels $\left(F_{(3,36)}=6.23, P<0.05\right.$ vs. CYP group for serum; $F_{(3,36)}=10.39, P<0.001$ vs. CYP group for CSF) after 12 days of treatment, as measured on day 20 after the first injection. Additionally, L-TAMS did not affect the $\mathrm{Mg}^{2+}$ level in either the serum or the CSF of normal rats.

We next performed a linear regression analysis to explore the relationship between $\mathrm{Mg}^{2+}$ level and 
mechanical withdrawal threshold, as well as the relationship between $\mathrm{Mg}^{2+}$ level and floating time in the FST or recognition index in NORT. The results indicate that the concentrations of $\mathrm{Mg}^{2+}$ in serum and CSF were both positively correlated with the mechanical withdrawal threshold (Fig. 2e, h) and recognition index (Fig. 2f, i), whereas there were negative correlations with floating time (Fig. 2g, j).

\section{Reversal of magnesium deficiency with L-TAMS leads to attenuation of mechanical allodynia, depressive-like behaviors, and short-term memory deficits (STMD)}

To investigate the effect of L-TAMS on mechanical allodynia in the CYP-induced cystitis model, we designed two experiments: L-TAMS was administered pre- (Fig. 3a) and post-CYP-induced cystitis model establishment (Fig. 3b) to determine its preventive and therapeutic effect on mechanical allodynia, respectively (also shown in Fig. 1b). As shown in Fig. 3a, b, L-TAMS began to significantly attenuate the decrease in the mechanical withdrawal threshold in the cystitis model from day 12 after the first CYP injection $\left(F_{(2,21)}=108.2, P<0.05\right.$ vs. CYP group for "a"; $F_{(3,52)}=107.6, P<0.01$ vs. CYP group for " $\mathrm{b}$ "). The thresholds in the CYP + L-TAMS group in the two experiments both gradually increased to the basal level from day 12. On day 20, the difference in the threshold between the CYP + L-TAMS and vehicle groups was no longer significant. We also found that the application of L-TAMS did not affect the mechanical withdrawal threshold of normal rats.

In addition, the effect of L-TAMS on depressive-like behavior and short-term memory ability was determined using the FST, SPT, and NORT, respectively. Considering that FST itself is a test that can influence depressivelike behavior [34], we only performed the test once. The FST performed on day 20 shows that the floating time in the cystitis rats was significantly longer than that of the vehicle rats $(P<0.001)$. Moreover, the cystitis group that received L-TAMS treatment showed a shorter floating time than those without L-TAMS treatment $\left(F_{(3,16)}\right.$ $=54.96, P<0.001$ ) (Fig. 3c). Additionally, the SPT result shown in Fig. $3 \mathrm{~d}$ indicated that the reduced sucrose preference ratio present in the CYP-induced cystitis group also returned to basal level after L-TAMS treatment ( $F$ $(3,16)=5.46, P<0.01$ vs. CYP group). NORT was performed on day 8 (the day after the last CYP injection and prior to L-TAMS treatment) to determine the short-term memory ability in the cystitis group. No significant change was found in the two cystitis groups. However, after a 10day treatment with L-TAMS, on day 18 , the recognition index between the cystitis group with and without LTAMS treatment became significantly different $\left(F_{(3,36)}=\right.$ 41.71, $P<0.001)$. The recognition index of the cystitis model with L-TAMS treatment increased back to basal level on day 18 (Fig. 3e). Additionally, all the FST, PST, and NORT results in the normal animals were not affected by oral application of L-TAMS (Fig. 3c-e).

TNF- $\alpha /$ NF-KB signaling and IL-1 $\beta$ were upregulated in the SDH and hippocampus of the CYP-induced cystitis model, and inhibition of NF-KB signaling attenuated mechanical allodynia, depressive-like behavior, and STMD

Upregulations of TNF- $\alpha / \mathrm{NF}-\kappa \mathrm{B}$ signaling as well as the pro-inflammatory factor IL- $1 \beta$ in the spinal cord are important neuroinflammatory mechanisms in neuropathic pain [35]. Neuroinflammation initiated by TNF- $\alpha$ located at the hippocampus could be a common mechanism between pain and depression [36] or memory deficits [37]. However, the role of TNF- $\alpha / N F-k B$ signaling and IL- $1 \beta$ expression in the SDH and hippocampus of the CYPinduced cystitis model has not yet been clearly identified.

We performed western blot analyses to examine TNF- $\alpha$ / NF- $\mathrm{kB}$ signaling and IL- $1 \beta$ expression in the SDH and hippocampus harvested on days 8,12 , and 20 . As shown in Fig. $4 \mathrm{a}-\mathrm{c}, \mathrm{TNF}-\alpha$, the $p$-p65/p65 ratio, and IL- $1 \beta$ were all significantly upregulated in the SDH at all three time points when compared with the vehicle group. Similar overexpression of the above factors was also found in the hippocampus of rats in the cystitis model group (Fig. $4 \mathrm{~d}-\mathrm{f}$ ).

Furthermore, we explored the co-localization of TNF- $\alpha$, p-p65 (a principal transcriptional regulator of the activation of the NF-kB pathway), and IL-1 $\beta$ in the SDH and hippocampus of cystitis model rats using double immunofluorescence staining. The results indicate that both in the SDH and hippocampus, all three proteins co-localized with NeuN-labeled neurons but not with GFAP-labeled astrocytes or OX-42-labeled microglia (Figs. 5 and 6).

To further validate the role of pro-inflammatory NF- $\mathrm{kB}$ signaling in the mechanism of mechanical allodynia and comorbid depressive-like behaviors or STMD in the cystitis model, we used PDTC, an inhibitor of NF- $\mathrm{kB}$ signaling, to evaluate its influence on the behavioral test results. As Fig. 7 shows, intrathecal injection of PDTC (200 ng per day for three consecutive days) could reverse the mechanical allodynia induced by CYP-induced cystitis, as well as return pain-associated depressive-like behaviors and STMD to a basal level.

\section{Oral application of L-TAMS inhibits the upregulation of TNF- $\alpha / N F-K B$ signaling and IL- $1 \beta$ in the SDH and hippocampus of CYP-induced cystitis rats}

A previous study indicated that L-TAMS attenuated vincristine-induced allodynia via inhibition of TNF- $\alpha /$ NF- $\kappa B$ signaling [38] in the SDH, and could restore memory deficits in spare nerve injury (SNI) rats through inhibition of TNF- $\alpha$ at a hippocampal level [14]. Combined with the upregulation of TNF- $\alpha / \mathrm{NF}-\mathrm{\kappa B}$ signaling and IL-1 $\beta$ found in both the SDH and hippocampus of 


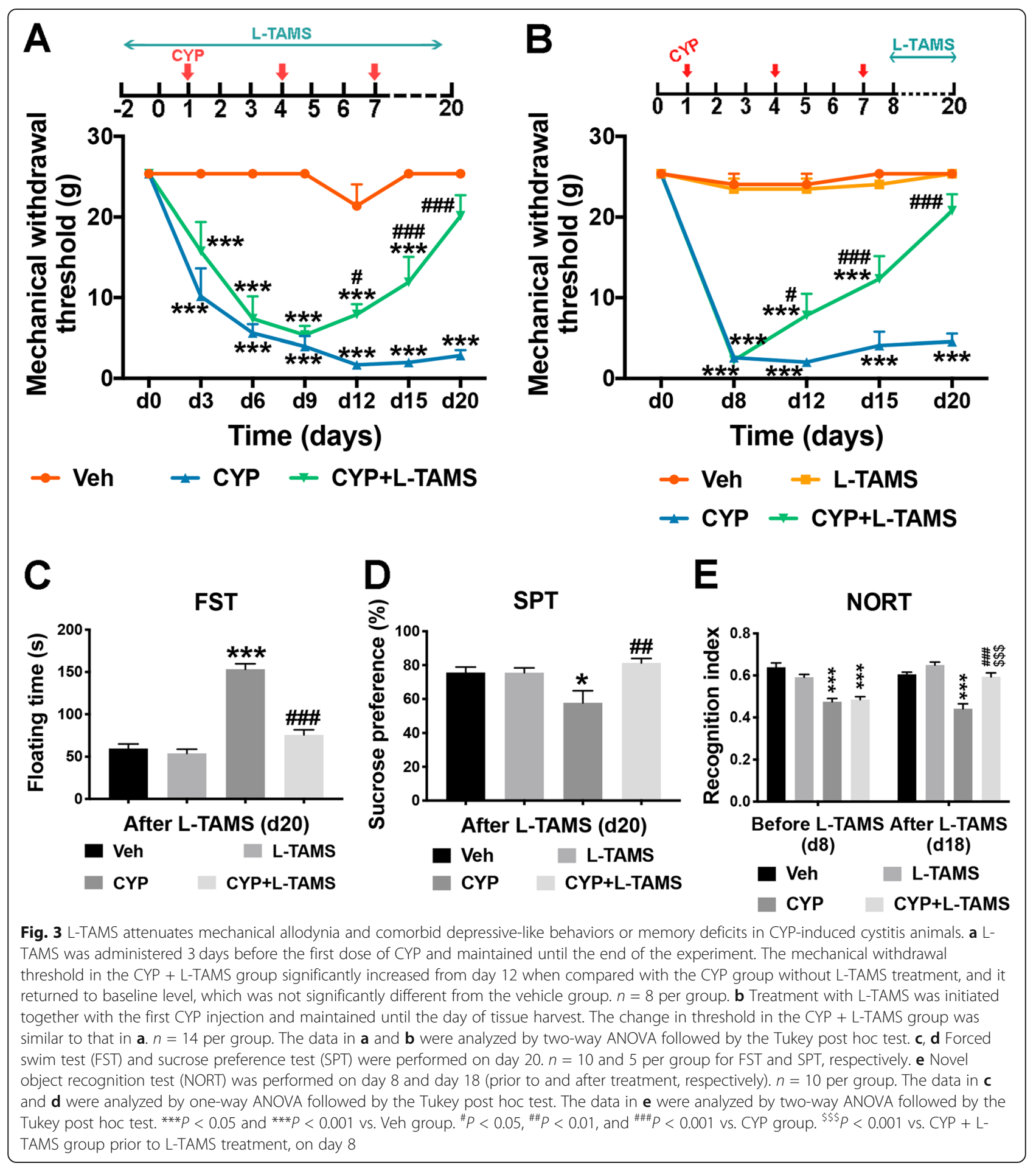

cystitis model rats, we hypothesized that oral application of L-TAMS could attenuate mechanical allodynia, memory deficits, and depressive-like behaviors through inhibition of TNF- $\alpha / N F-\kappa B$ signaling and IL- $1 \beta$ in the SDH and hippocampus of cystitis rats.

Therefore, we performed a western blot analysis and immunofluorescence staining to determine TNF- $\alpha / N F-$ $\kappa B$ signaling as well as IL- $1 \beta$ expression in the SDH and hippocampus of CYP-induced cystitis rats and compared the expression level between groups with and without LTAMS treatment. The results of the western blot analysis indicate that the upregulation of TNF- $\alpha$, the $p$-p65/ p65 ratio, and IL-1 $\beta$ in the SDH of the cystitis model following L-TAMS treatment was all significantly inhibited 

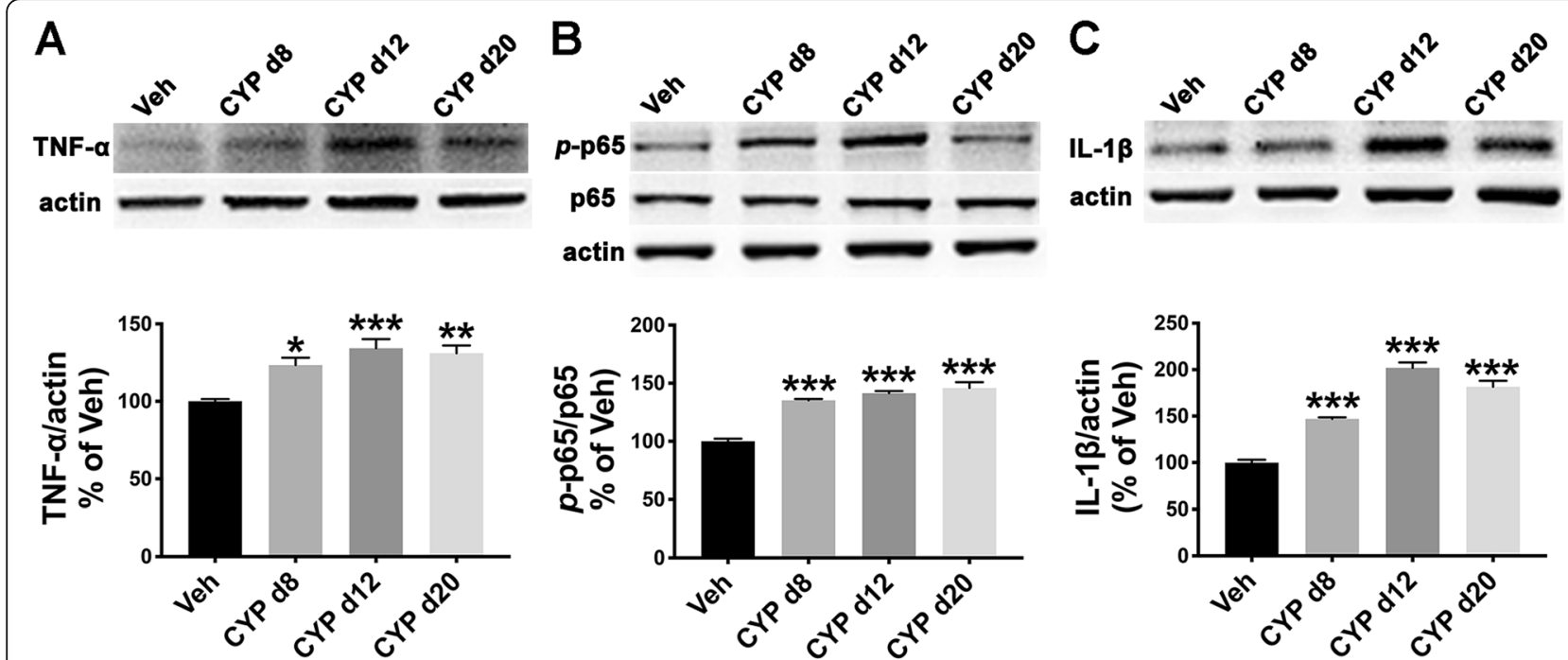

D

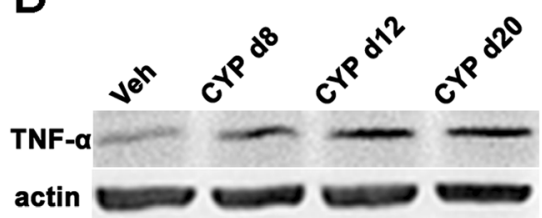

E

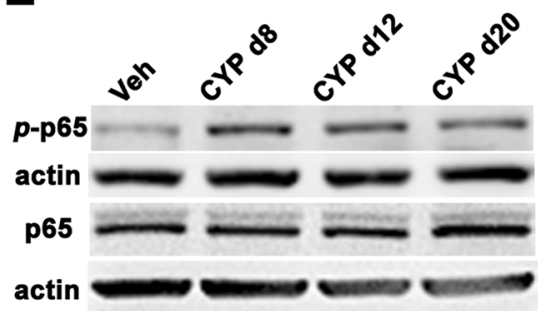

$\mathbf{F}$
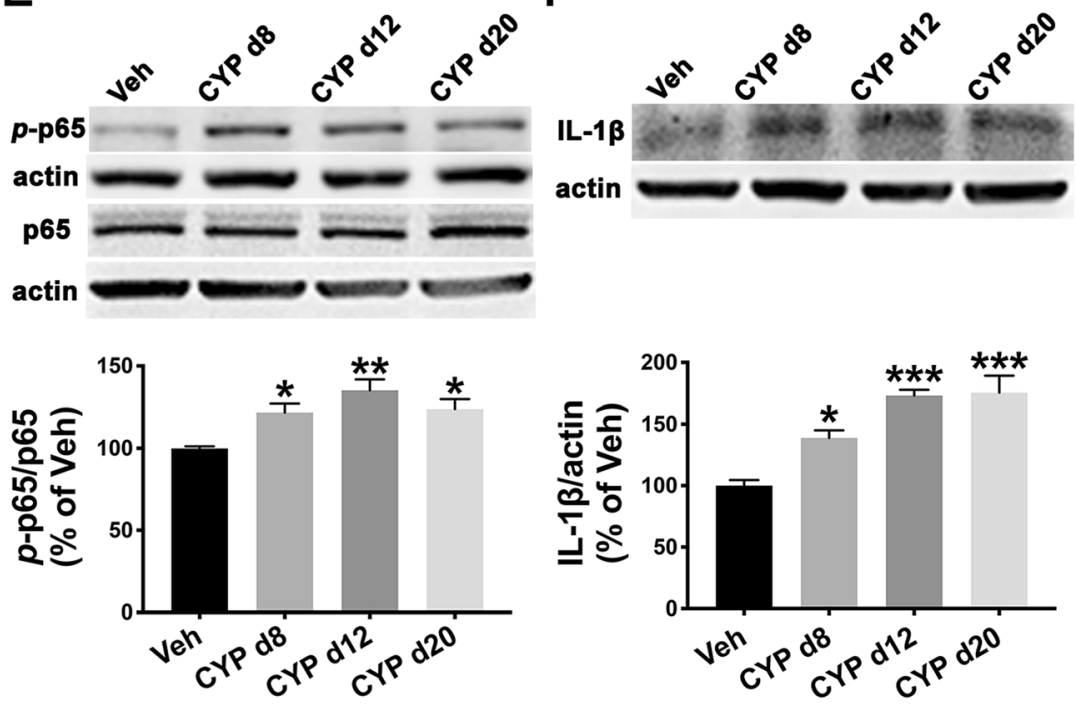

Fig. 4 TNF- $\alpha$ /NF-KB signaling and IL-1 $\beta$ were upregulated in the SDH and hippocampus of the CYP-induced cystitis model. a-c Western blot analysis results indicate that TNF-a, the phospho-p65 ( $p$-p65)/p65 ratio, and IL-1 $\beta$ were increased in the SDH of the CYP-induced cystitis model at all three time points (days 8, 12, and 20) after CYP injection. $\mathbf{d}-\mathbf{f}$ TNF-a, the $p$-p65/p65 ratio, and IL-1 $\beta$ also showed higher expression in the hippocampus of the cystitis group than in the Veh group at the three time points. ${ }^{*} P<0.05,{ }^{* *} P<0.01$, and ${ }^{* * *} P<0.001$ vs. Veh group. The data were analyzed by one-way ANOVA followed by the Tukey post hoc test

on day 20 when compared with the cystitis group without L-TAMS treatment (Fig. $8 \mathrm{a}-\mathrm{c}$ ). Moreover, as shown in Fig. 8d-f, overexpression of TNF- $\alpha$, the $p$-p65/p65 ratio, and IL-1 $\beta$ in the hippocampus of cystitis animals was also prevented after L-TAMS treatment when compared to the group without treatment. The immunofluorescence results also show a similar change to that of the western blot analysis (Figs. 9 and 10). Furthermore, the western blot and immunofluorescence analyses both showed that the expression of TNF- $\alpha$, IL- $1 \beta$, and the $p$ p65/p65 ratio in the CYP + L-TAMS group became non-significantly different from that in the vehicle group. Additionally, the expression difference of TNF- $\alpha / N F-k B$ signaling and IL-1 $\beta$ between the vehicle and L-TAMS groups was non-significant.

Up- and downregulation of NR2B in the SDH and hippocampus, respectively, were normalized by oral application of L-TAMS in the CYP-induced cystitis model NMDA receptor (NMDAR), especially the NR2B subunit, plays a key role in synaptic plasticity. Activation of $\mathrm{NR} 2 \mathrm{~B}$ in the SDH is critically associated with neuropathic pain [39, 40]. However, the downregulation of NR2B in the hippocampus would impair synaptic plasticity contributing to memory deficits [41] and the downregulation has also been observed in the hippocampus of 

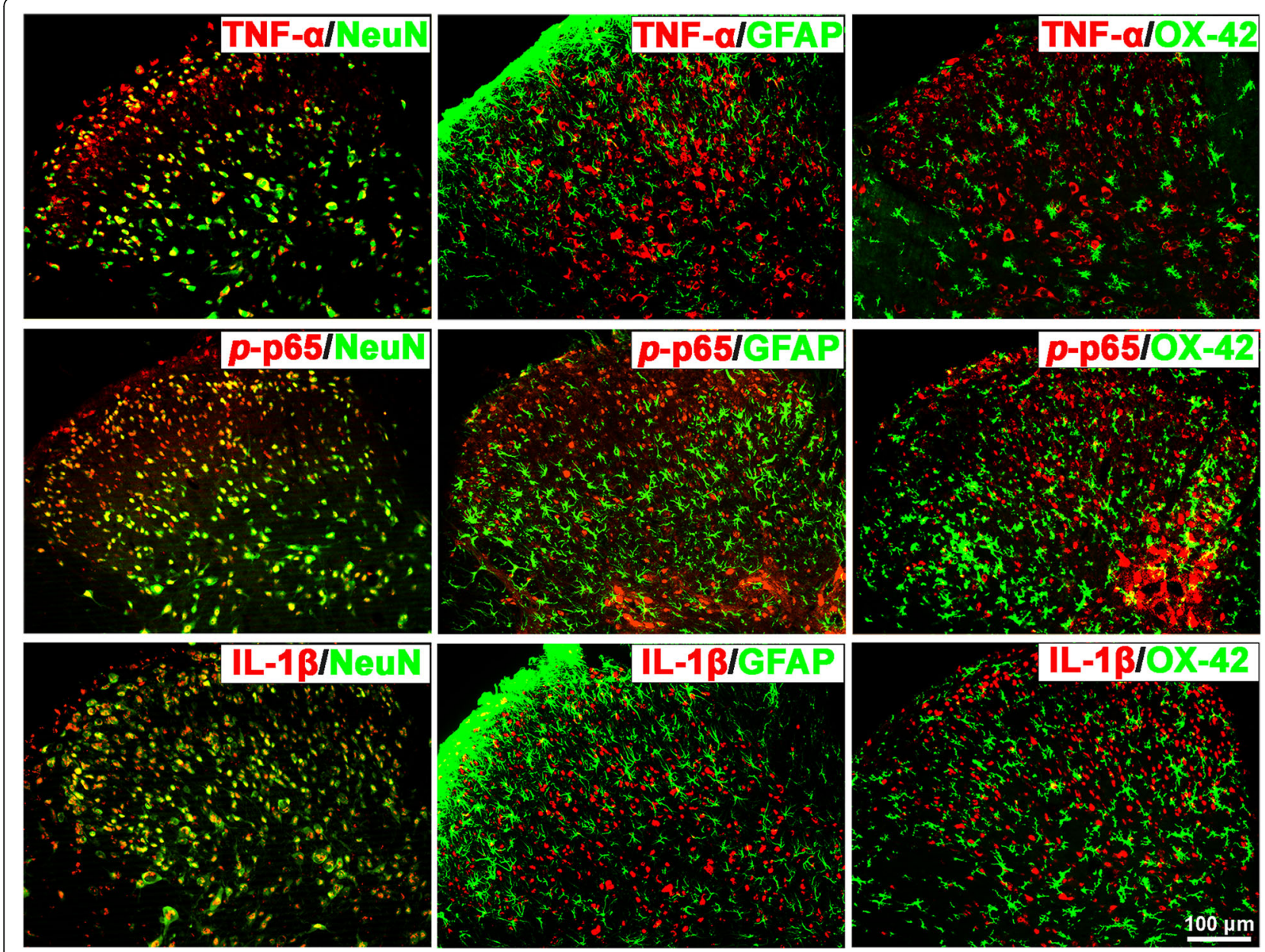

Fig. 5 TNF- $a, p-p 65$, and IL-1 $\beta$ all co-localize with NeuN in the SDH of CYP-induced cystitis rats. Photographs of the double immunofluorescence staining indicate that TNF-a, $p$-p65 (a principal transcriptional regulator of the activation of NF-kB pathway), and IL-1 $\beta$ were only co-localized with NeuN-labeled neurons but not with GFAP-labeled astrocytes or OX-42-labeled microglia in the SDH of cystitis animals

a rat model of depression [42, 43]. Besides, NR2B can be modulated by $\mathrm{Mg}^{2+}$ [44] as well as TNF- $\alpha$ [14]. Therefore, we speculated that expression of NR2B in the SDH and hippocampus of the CYP-induced cystitis model may have a similar opposite change at the two central nerve system levels, and magnesium supplementation with L-TAMS could normalize the change.

We explored the expression of NR2B in the SDH and hippocampus of the cystitis model using western blot analysis. The result indicated that NR2B in the SDH was significantly upregulated at the three time points (Fig. 11a), whereas it was downregulated in the hippocampus at the three time points (Fig. 11b). Additionally, the overexpression of NR2B in the SDH was inhibited by L-TAMS application for 12 days, as assessed on day 20 following the first CYP injection (Fig. 11c), and the low-expression of NR2B in the hippocampus was also reversed on day 20 (Fig. 11d). We did not find any effect of L-TAMS on NR2B expression in normal rats (Fig. 11c, d).

\section{Discussion}

In our present research, we revealed that there is a magnesium deficiency in both the serum and CSF of CYPinduced cystitis model rats. The magnesium deficiency was positively correlated with both mechanical allodynia and comorbid depressive-like behaviors and memory deficits. As a magnesium compound that can elevate brain magnesium by oral administration, L-TAMS was able to reverse the magnesium deficiency in the cystitis model and to attenuate the mechanical allodynia as well as the comorbid depressive-like behaviors and memory deficits. Neuroinflammation and synaptic plasticity play an important role in the mechanism of CYP-induced cystitis, and we found that TNF- $\alpha / N F-\kappa B$ signaling and IL- $1 \beta$ were upregulated in both the SDH and hippocampus of the cystitis model. However, the NR2B subunit of NMDA $\mathrm{R}$ showed opposing expression at the two different central nerve system levels, showing greater expression in the $\mathrm{SDH}$ but less in the hippocampus. Surprisingly, oral 

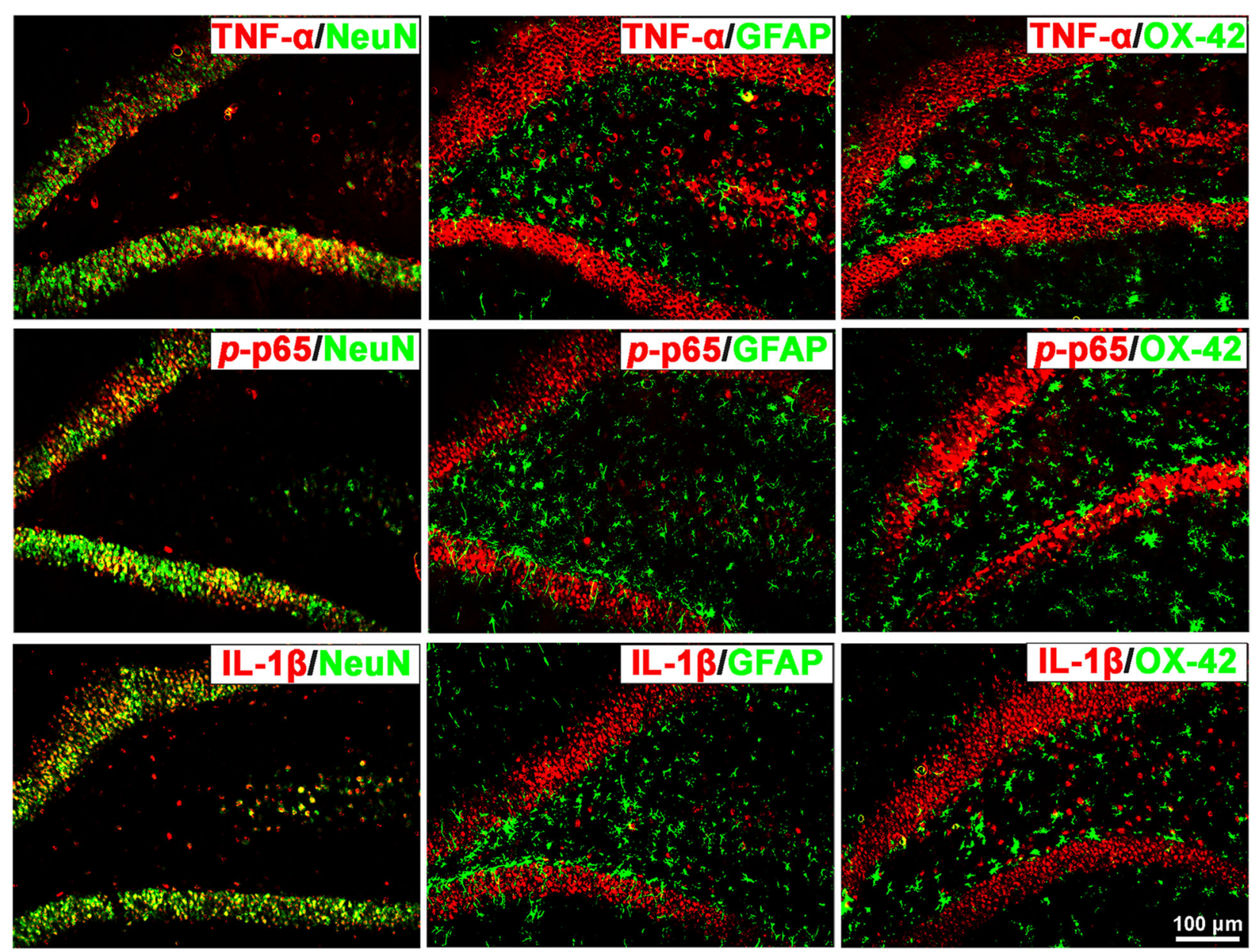

Fig. 6 TNF-a, $p$-p65, and IL-1 $\beta$ co-localized with NeuN in the hippocampus of the CYP-induced cystitis model. Double immunofluorescence staining indicates that TNF- $a, p-p 65$, and IL-1 $\beta$ were also co-localized with NeuN but not with GFAP or OX-42 in the hippocampus of cystitis animals

application of L-TAMS could reverse and normalize the expression changes in TNF- $\alpha / \mathrm{NF}-\mathrm{k} B$ signaling, IL-1 $\beta$, and $\mathrm{NR} 2 \mathrm{~B}$ in both the SDH and hippocampus of the CYPinduced cystitis model. Taken together, L-TAMS attenuated mechanical allodynia, depressive-like behavior, and memory deficits in CYP-induced cystitis model rats through prevention of magnesium deficiency and abnormal regulation of TNF- $\alpha / \mathrm{NF}-\mathrm{kB}$ signaling, IL- $1 \beta$, and the NR2B subunit in the SDH and hippocampus.

The role of magnesium deficiency in mechanical allodynia and the comorbid depressive-like behaviors and memory deficits in the cystitis model

As mentioned in the "Background" section, it is believed that patients with $\mathrm{BPS} / \mathrm{IC}$ are at greater risk of having depression and memory problems. However, no research has revealed the mechanism underlying the comorbidity of bladder-related pain and depression or memory dysfunction in BPS/IC. Our present work did not focus on clarifying such a complex mechanism, but instead, we focused on establishing a common therapeutic target for both bladder-related pain and the accompanying depression and memory dysfunction. Such research could be of clinical value for the treatment of BPS/IC.

Magnesium deficiency could be an underlying cause accounting for both bladder-related pain and comorbid depression and memory dysfunction in BPS/IC. Previous studies showed that magnesium deficiency in rats, induced by a Mg-depleted diet, showed hyperalgesia, which could be attenuated by supplementation with $\mathrm{MgSO}_{4}[11,12]$. Moreover, magnesium deficiency is also associated with the neuropathic pain produced by diabetes [10, 45] and chemotherapy agents $[24,46]$. Although visceral pain differs a lot from neuropathic pain, our present study showed magnesium deficiency in both the serum and CSF of cystitis rats. Furthermore, $\mathrm{Mg}^{2+}$ levels in the serum or CSF were positively correlated with the mechanical withdrawal threshold. Based on the above findings, supplementation 


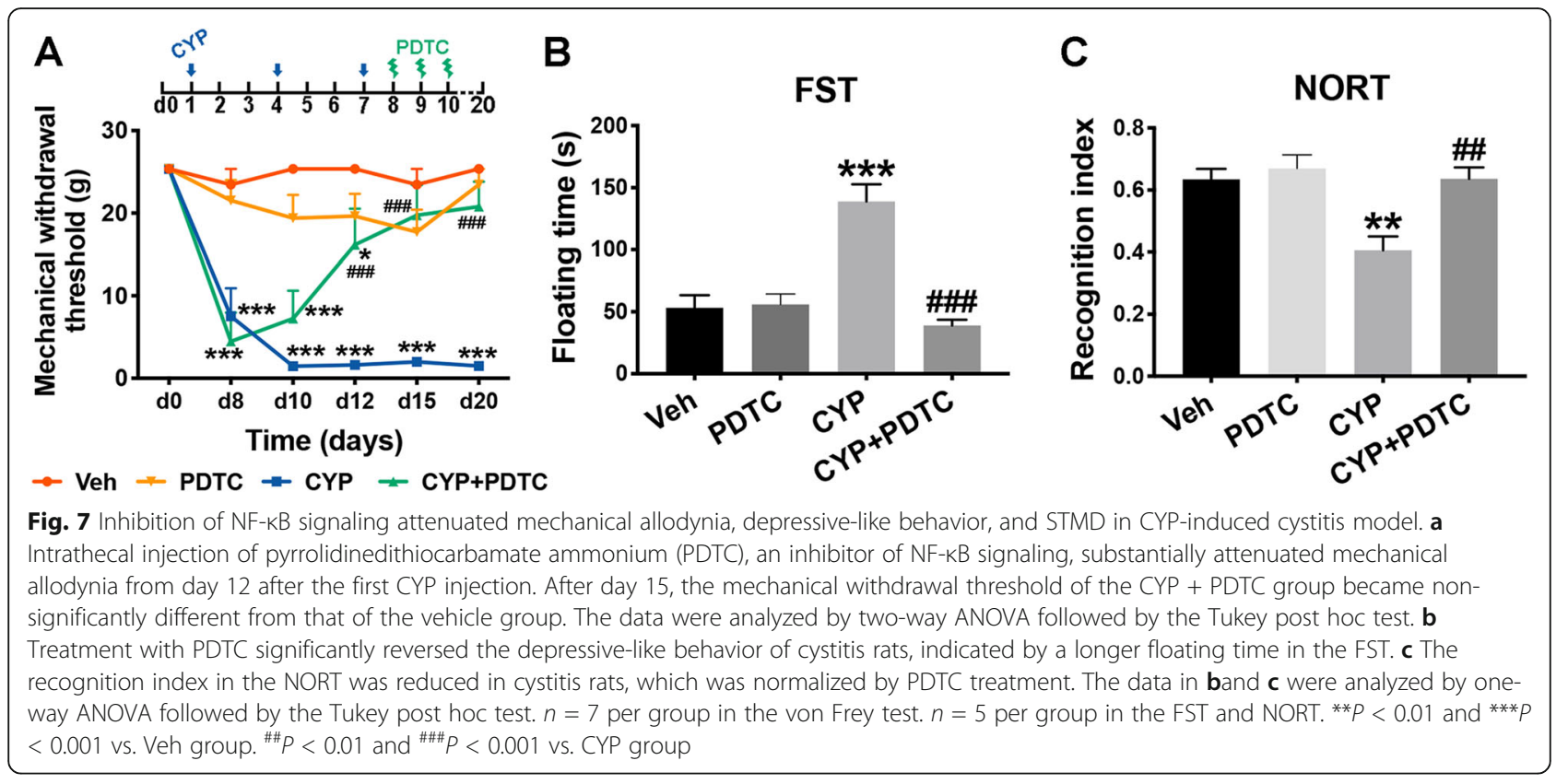

of magnesium was taken into account to attenuate mechanical allodynia in the cystitis model. However, some basic and clinical research reported a negative effect of magnesium compounds on pain. One group demonstrated that oral administration of $\mathrm{MgCl}_{2}$ failed to reduce neuropathic pain in patients [47]. A significant antinociceptive effect of i.t. administration of $\mathrm{MgSO}_{4}$ was not observed in an acute pain model [48]. Additionally, the effect of the perioperative use of $\mathrm{MgSO}_{4}$ on postoperative pain is still controversial [49]. The unsatisfying elevation of magnesium levels in the CSF possibly accounts for the negative therapeutic outcome of $\mathrm{MgCl}_{2}$ and $\mathrm{MgSO}_{4}$. Research has indicated that the perioperative use of $\mathrm{MgSO}_{4}$ could not successfully elevate the magnesium concentration in the CSF and this was negatively correlated with cumulative postoperative analgesic consumption [50]. Likewise, $\mathrm{MgCI}_{2}$ injected i.p. was unable to change the brain magnesium level in rats [51]. Therefore, we intended to find a suitable magnesium compound that is more effective at elevating brain $\mathrm{Mg}^{2+}$. We therefore used L-TAMS, which has been validated to more efficiently transport $\mathrm{Mg}^{2+}$ into the central nervous system [22]. Our present work shows that oral application of L-TAMS was able to normalize the reduced $\mathrm{Mg}^{2+}$ level both in the serum and CSF of cystitis rats. More importantly, L-TAMS could attenuate the mechanical allodynia in cystitis rats, though pre-treatment could not prevent the onset of allodynia.

In addition, it has been well established that a magnesium-deficient diet leads to depressive behavior [52] and impairments in emotional memory [53] in normal mice. Moreover, magnesium treatment has been successfully used to treat major depression [54] and treatmentresistant depression [55]. Increasing brain magnesium using
L-TAMS enhances short- and long-term memory in both young and aged rats [22]. As comorbidities of bladderrelated pain, depression and memory deficits may share some common pathological mechanisms with the above conditions. Interestingly, we showed that magnesium deficiencies in both the serum and CSF were associated with depressive behavior or STMD in the cystitis model. The results share some points of similarity with a previous result showing that $\mathrm{Mg}^{2+}$ levels in serum were correlated with both pain scores and the depression index in patients with fibromyalgia [13]. Coincidently, the prevalence of fibromyalgia is much higher in patients with BPS/IC [56], indicating that the two syndromes may share common pathogenesis and pathophysiology. Our present work also showed that L-TAMS was able to normalize the depressive behavior and STMD in cystitis rats. The results further suggest that magnesium deficiency may contribute to the accompanying depression and memory deficits.

\section{The mechanisms by which normalization of magnesium deficiency attenuated mechanical allodynia and comorbidities}

It is widely believed that NF- $\mathrm{BB}$ signaling is a critical proinflammatory pathway, and $p$-p65 is a principal transcriptional regulator of the activation of the NF- $k B$ pathway [57]. TNF- $\alpha$ is a classical and canonical factor that stimulates the phosphorylation of p65 and helps it transfer to the nucleus where it activates numerous target genes, including TNF- $\alpha$ itself and IL-1 $\beta$ [58].

It has long been proposed that TNF- $\alpha / \mathrm{NF}-\mathrm{kB}$ signaling plays a crucial role in pathological pain [59]. Additionally, TNF- $\alpha / \mathrm{NF}-\mathrm{kB}$ signaling has also been shown to be involved in the development of depression [60] and the 


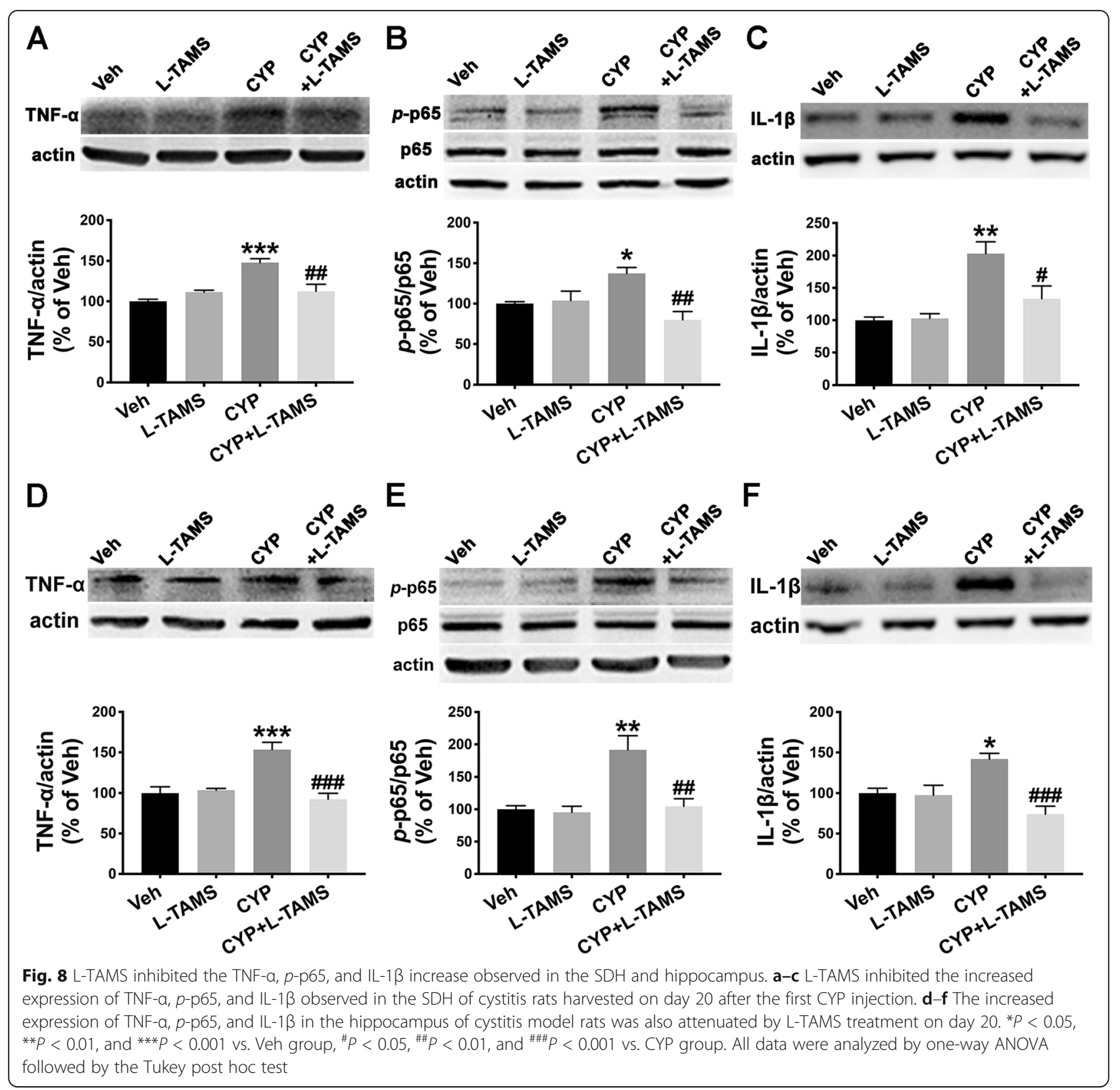

regulation of memory [61]. Therefore, the question is, can TNF- $\alpha / N F-\kappa B$ signaling act as a promotor in the mechanism of comorbidities of pain such as depression or memory deficits? Research has indicated that during the development of chronic neuropathic pain, persistent noxious stimuli could result in an increase in TNF- $\alpha$ in the hippocampus, which then disrupts the depressionrelated brain circuit of hypothalamic-pituitary-adrenal axis dysfunction [36]. Overexpression of TNF- $\alpha$ in the hippocampus was also revealed to lead to neuropathic pain and memory deficits in the SNI model [62]. Additionally, TNF- $\alpha$ can potentiate positive feedback to produce more TNF- $\alpha$ through the NF- $\mathrm{BB}$ pathway, worsening the seriousness of pain and the depressivelike symptoms and memory deficits. Based on the above evidence, we hypothesize that TNF- $\alpha / \mathrm{NF}-\mathrm{kB}$ signaling is an underlying mechanism of bladder-related pain and comorbid depressive-like behaviors and memory impairment in the cystitis model. The results in our present study showed that TNF- $\alpha / N F-\kappa B$ signaling was activated and more IL- $1 \beta$ was produced at both the spinal cord and hippocampal level. Furthermore, inhibition of the NF- KB pathway showed a therapeutic effect on mechanical allodynia and comorbid depressive-like behaviors or STMD, validating the role of NF- $\kappa B$ signaling in the mechanism common to the comorbidities of pain and 


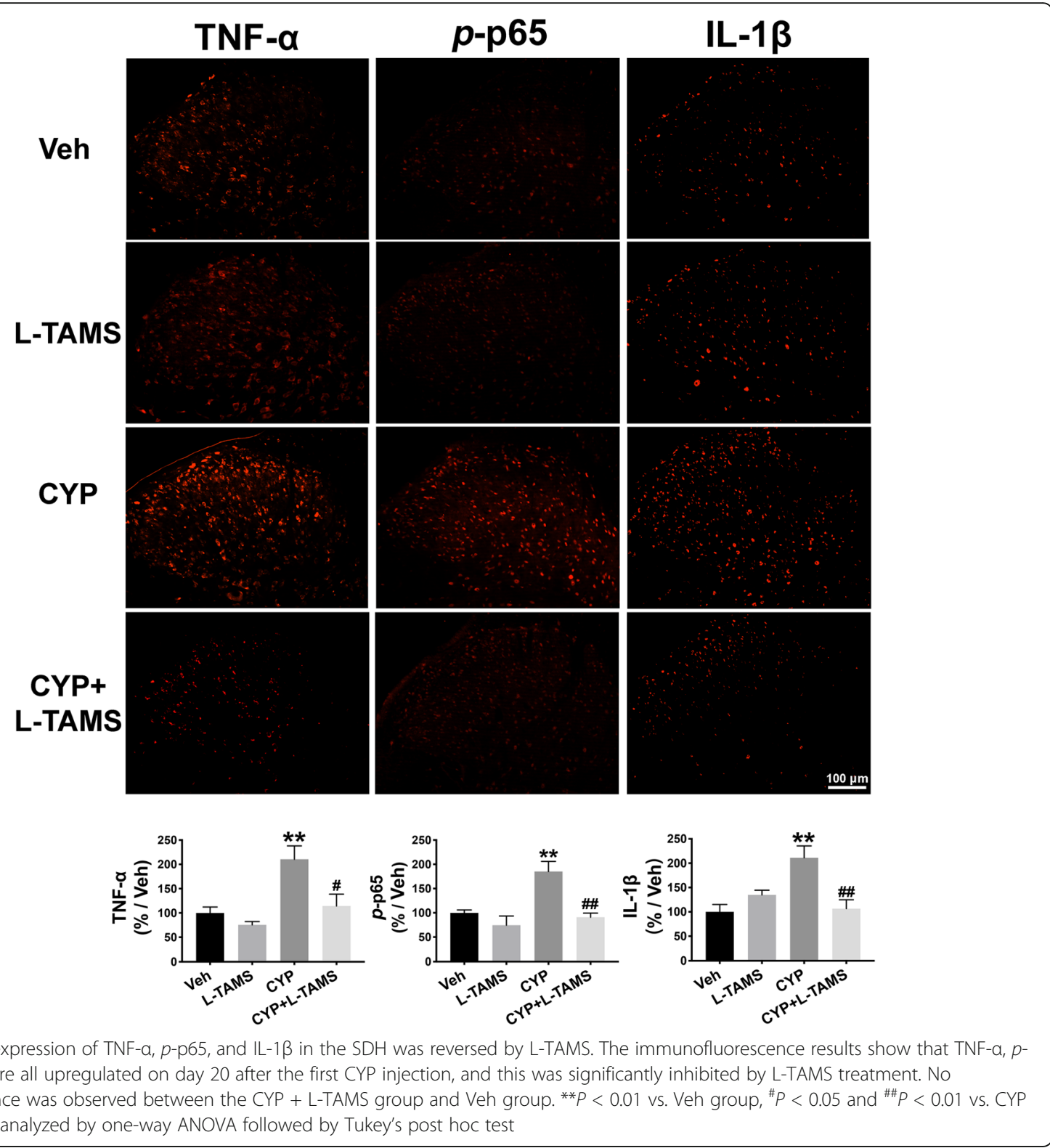

depressive-like behaviors or memory dysfunction in the cystitis model.

Next, we explored whether TNF- $\alpha / N F-\kappa B$ signaling is associated with magnesium deficiency in vivo. A previous study provides evidence that magnesium-deficient animals exhibit a generalized inflammatory tone induced by elevated circulating levels of the proinflammatory cytokines TNF- $\alpha$ and IL-1 $\beta$ [20]. Aged animals also present with similar increases in proinflammatory cytokines [20]. In our present work, reversal of magnesium deficiency with L-TAMS normalized the upregulation of TNF- $\alpha / N F-\kappa B$ signaling and the associated increase in IL- $1 \beta$. The result is somewhat consistent with that in the vincristine-induced pain [24], SNI [14], and AD [63] models. Taken together, upregulation of TNF- $\alpha / N F-\kappa B$ signaling and the associated increase in IL-1 $\beta$ are underlying downstream mechanisms of magnesium deficiency in the CYP-induced cystitis model.

Synaptic plasticity is an important mechanism involved in the regulation of pain, depression, and memory function. TNF- $\alpha$ is not only a promotor of neuroinflammation, but also a regulator of synaptic plasticity. A previous study showed that overproduction of TNF- $\alpha$ can induce long-term potentiation (LTP) in the SDH [64] but inhibit LTP in the hippocampus [37] of a nerve injury model, which ultimately leads to pain and memory deficits, respectively. NMDARs, especially NR2B subunit-containing NMDARs, are believed to be activators of LTP. In our present work, we did not directly examine LTP in our cystitis model, but instead focused 


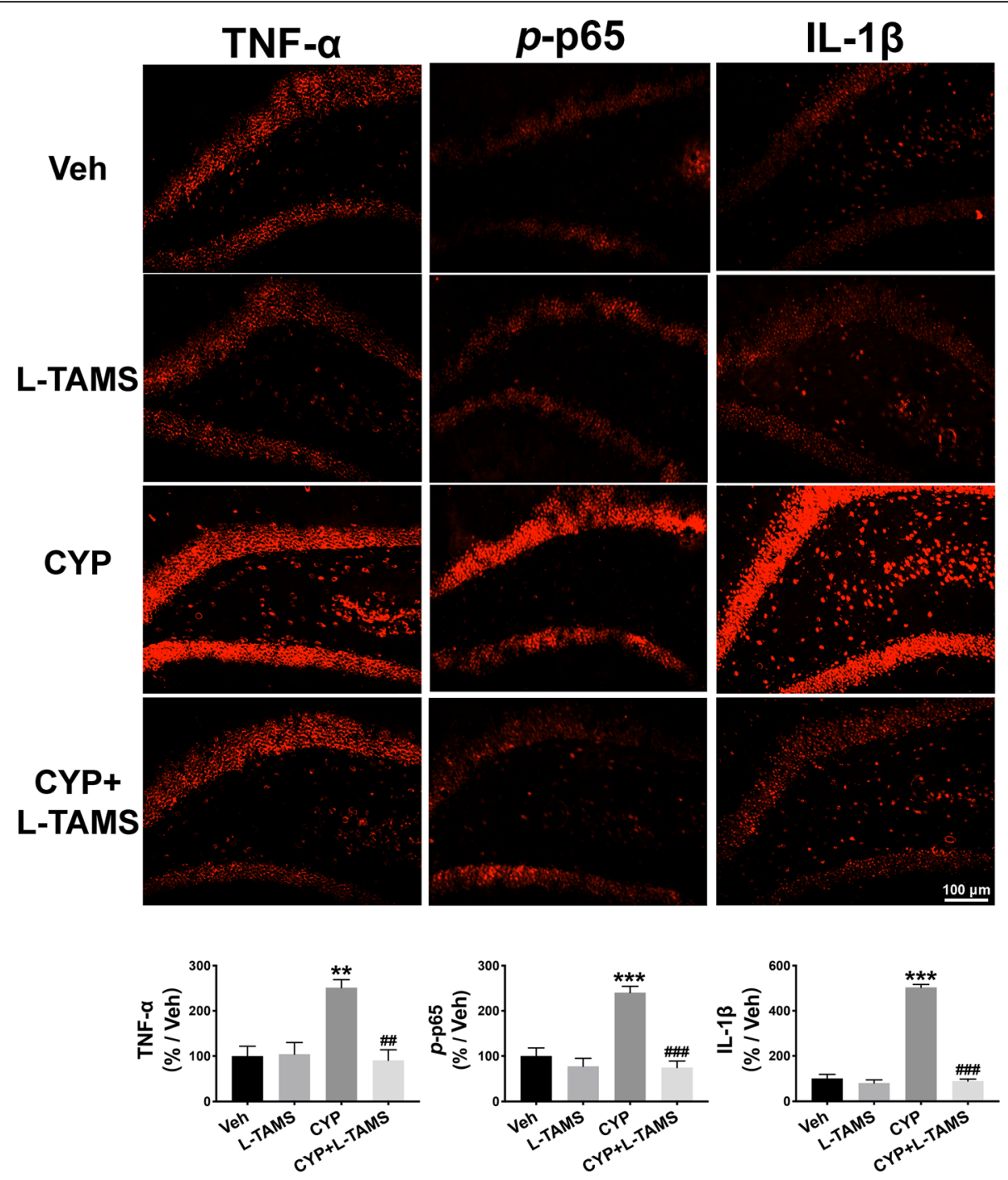

Fig. 10 Upregulation of TNF- $a, p-p 65$, and IL-1 $\beta$ in the hippocampus was reversed by L-TAMS. The expression of TNF- $a, p$-p65, and IL-1 $\beta$ were all found to be increased on day 20 after the first CYP injection. The expression of the three proteins in the cystitis group treated with L-TAMS was significantly lower than that in the untreated cystitis group. No significant difference was observed between the CYP + L-TAMS group and Veh group. ${ }^{* *} P<0.01$ and ${ }^{* * *} P<0.001$ vs. Veh group, ${ }^{\# \#} P<0.01$ and ${ }^{\# \# \#} P<0.001$ vs. CYP group. Data were analyzed by one-way ANOVA followed by Tukey's post hoc test

on the expression of the NR2B subtype. Interestingly, up- and downregulation of NR2B were observed in the $\mathrm{SDH}$ and hippocampus, respectively, of the cystitis model rats. The region-dependent differences in NR2B expression is in accordance with reports in many chronic pain conditions [65]. Upregulation of TNF- $\alpha$ in both the SDH and hippocampus could account for such differences, leading to spinal LTP and hippocampal LTD, respectively. Furthermore, it has been proposed that magnesium is an essential modulator of NMDAR. Therefore, $\mathrm{Mg}^{2+}$ could represent a target to modulate NR2B expression in the cystitis model. Surprisingly, our work revealed that L-TAMS could normalize rather than increase or decrease NR2B expression in the SDH and hippocampus. This result is consistent with that in the vincristine-induced allodynia model. We consider the opposing change in NR2B expression as an underlying mechanism of mechanical allodynia and memory deficits in cystitis rats, accounting for the therapeutic effect of L-TAMS on both mechanical allodynia and memory deficits of cystitis rats through normalization of NR2B expression. However, this hypothesis should be validated with more research.

Last but not least, TNF- $\alpha / N F-\kappa B$ signaling and IL- $1 \beta$ participate in many biological activities, including immunity, cell proliferation, differentiation, and apoptosis $[66,67]$, and as mentioned above, the NR2B subunit of NMDAR is an important modulator of synaptic 

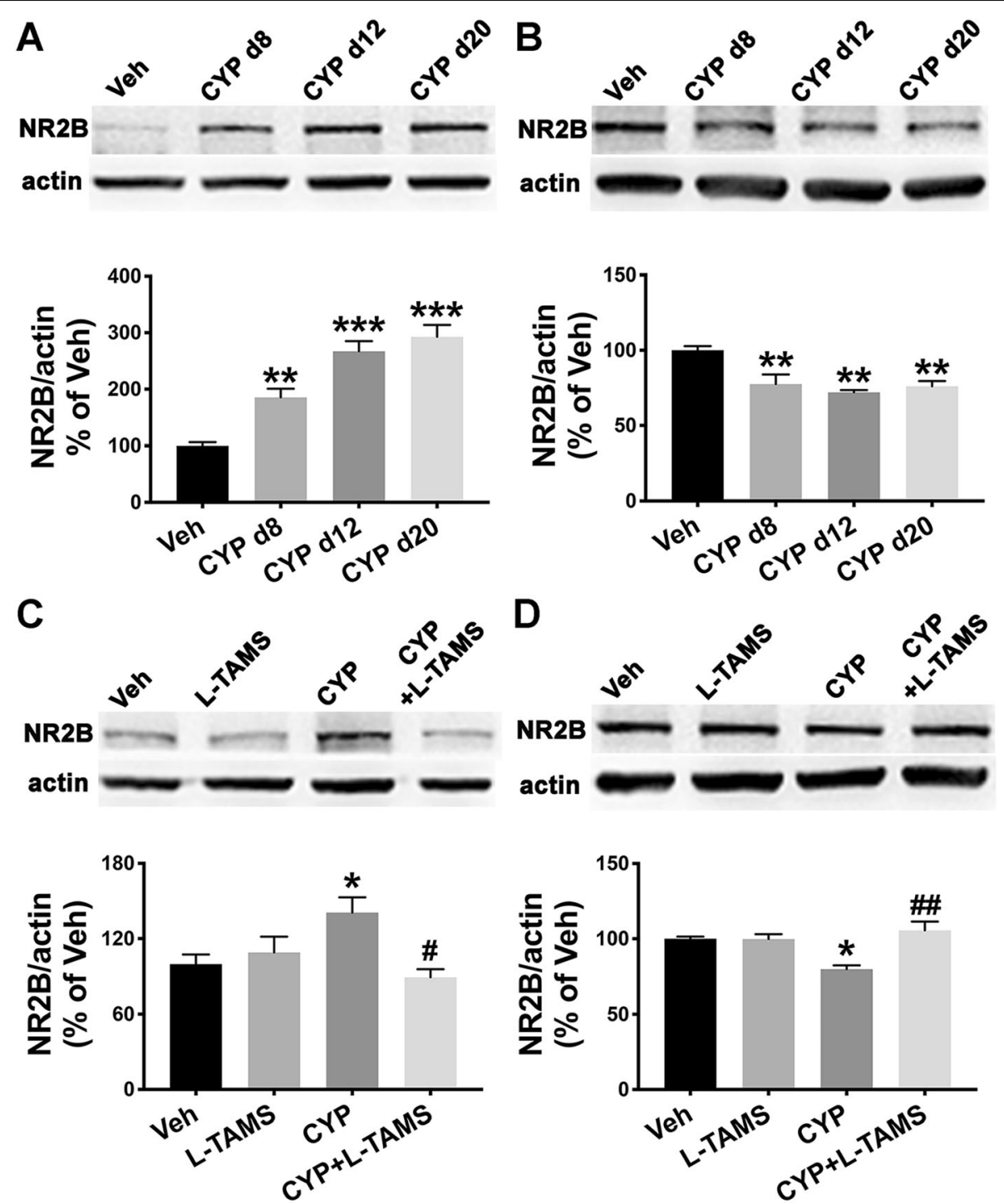

Fig. $11 \mathrm{Up}$ - and downregulation of NR2B in the SDH and hippocampus, respectively, were normalized by L-TAMS. Western blot analysis showed that NR2B was upregulated in the SDH (a) but downregulated in the hippocampus (b) of cystitis model rats at the three time points (days 8,12 , and 20 after the first CYP injection). The abnormal expression of NR2B in the SDH (c) or hippocampus (d) was neutralized by oral application of LTAMS on day $20 .{ }^{*} P<0.05,{ }^{* *} P<0.01$, and ${ }^{* * *} P<0.001$ vs. Veh group, ${ }^{\#} P<0.05$ and ${ }^{\# \#} P<0.01$ vs. CYP group. Data were analyzed by one-way ANOVA followed by Tukey's post hoc test

plasticity. Accordingly, it is quite important to maintain physiological levels to prevent any side effects. In our present work, L-TAMS did not affect the expression of the aforementioned proteins in normal animals. Interestingly, after treatment with L-TAMS, the abnormal expression of proteins in cystitis rats were all reversed to the level seen in vehicle-treated animals. Thus, L-TAMS may represent a suitable means to treat BPS/IC.

The main limitation of this study is that we only focused on two central nervous system regions, the SDH and hippocampus, to carry out the research on whether and how normalization of magnesium deficiency by LTAMS plays a role in the cystitis model. This limits our ability to clarify an integrated mechanism of comorbidities in the central nervous system. A further limitation is that we only investigated mechanisms in the hippocampus in this study, though many brain regions including the hippocampus, prefrontal cortex, and amygdala are involved in the initiation and development of nociceptive sensitization, depression, and memory deficits, which are complex processes. More research on the change in circuits among different brain regions in the cystitis model is needed to clarify such processes. Moreover, we need to further investigate the downstream mechanism of magnesium deficiency evoking bladder-related pain, depression, and memory deficits. Lastly, our results might 
have been affected by the estrus cycle phase of the examined female animals.

\section{Conclusions}

Magnesium deficiency in the serum and CSF is associated with mechanical allodynia, depressive-like behaviors, and memory deficits in the CYP-induced cystitis model. Moreover, TNF- $\alpha / \mathrm{NF}-\mathrm{kB}$ signaling and proinflammatory IL- $1 \beta$ were both upregulated in the SDH and hippocampus of the cystitis rats. However, expression of the NR2B subunit showed changes in opposing directions in the SDH and hippocampus. Oral application of L-TAMS substantially reversed the magnesium deficiency and upregulation of TNF- $\alpha / N F-\kappa B$ signaling and IL-1 $\beta$ and normalized the expression of NR2B. In turn, this led to the attenuation of mechanical allodynia, depressive-like symptoms, and memory deficits in the CYP-induced cystitis model. Our study revealed that magnesium supplementation with L-TAMS could be of great clinical value for the treatment of BPS/IC.

\section{Abbreviations}

BPS: Bladder pain syndrome; CSF: Cerebrospinal fluid:

CYP: Cyclophosphamide; FST: Forced swim test; GFAP: Glial fibrillary acidic protein; IC: Interstitial cystitis; IL-1B: Interleukin-1 beta; L-TAMS: Magnesium-LThreonate; NeuN: Neuronal nuclei; NF-kB: Nuclear factor-kB; NORT: Novel object recognition test; NR2B: N-Methyl-D-aspartate receptor type 2B subunit; PDTC: Pyrrolidinedithiocarbamate ammonium; SDH: Spinal dorsal horn; SPT: Sucrose preference test; STMD: Short-term memory deficits; TNFa: Tumor necrosis factor-a

\section{Supplementary information}

Supplementary information accompanies this paper at https://doi.org/10. 1186/s12974-020-01786-5.

Additional file 1: Table S1. Number of animals used in each behavioral test and molecular experiment (per group). Table S2. Antibody information. Figure S1. Identification of specificity of the antibody for $p$ p65 used in our study. The specificity of the antibody for p-p65 was identified by pre-absorption with $p$-p65 (\$311) blocking peptide provided by the manufacturer.

\section{Acknowledgements}

We would like to thank Haofeng Zheng and Jing Xu for their advice on our study. And thank Yun Ji, Pei-Wen Yao, and other members in Pain Research Center and Department of Physiology of Sun Yat-sen University for their technical assistance on experiment conduction.

\section{Authors' contributions}

This study was conceptualized and designed by XFZ, XGL, JLC, XZ, and BLL. $X H W, H L D, H L Z, F Y$, and MZS collected and assembled the data. The data was analyzed and interpreted by WBL, JCX, and ZJL. The manuscript was written by $J \mathrm{LC}, Z X$, and $B L L$ and revised by XFZ and XGL. The authors read and approved the final manuscript.

\section{Funding}

This study was funded by grants from the National Natural Science Foundation of China (nos. 81670688 and 81800666), Guangdong Province Natural Science Foundation of China (nos. 2016A030313192, 2017A030310414, and 2018A0303130330), Guangdong Province Medical Science and Technology Research Foundation Project of China (no. A2017365), and Youth Teacher Cultivation Project of Sun Yat-sen University (no. 19ykpy33).

\section{Availability of data and materials}

The authors should be contacted if any data or material is required to be provided.

\section{Ethics approval and consent to participate}

All experimental procedures were approved by the Animal Care Committee of Sun Yat-sen University and conducted in accordance with the guidelines of the National Institutes of Health on animal care and ethical guidelines.

\section{Consent for publication}

All authors approved the version to be published.

\section{Competing interests}

The authors declare that they have no competing interests.

\section{Author details}

${ }^{1}$ Department of Urology, The Third Affiliated Hospital of Sun Yat-sen University, 600 W Tianhe Rd, Guangzhou 510630, China. ${ }^{2}$ Pain Research Center and Department of Physiology, Zhongshan School of Medicine, Sun Yat-sen University, 74 Zhongshan Rd. 2, Guangzhou 510080, China. ${ }^{3}$ Guangdong Provincial Key Laboratory of Brain Function and Disease, 74 Zhongshan Rd. 2, Guangzhou 510080, China. ${ }^{4}$ Department of Rehabilitation, The Third Affiliated Hospital and Lingnan Hospital of the Sun Yat-sen University, 2693 Kaichuang Rd, Guangzhou 510700, China.

Received: 16 September 2019 Accepted: 25 March 2020

Published online: 02 April 2020

\section{References}

1. Miller LR, Cano A. Comorbid chronic pain and depression: who is at risk? J Pain. 2009;10:619-27.

2. Hart RP, Martelli MF, Zasler ND. Chronic pain and neuropsychological functioning. Neuropsychol Rev. 2000;10:131-49.

3. Clemens JQ, Meenan RT, Rosetti MC, Gao SY, Calhoun EA. Prevalence and incidence of interstitial cystitis in a managed care population. J Urol. 2005 173:98-102 discussion 102

4. Oravisto KJ. Epidemiology of interstitial cystitis. Ann Chir Gynaecol Fenn. 1975;64:75-7.

5. Berger RE, Miller JE, Rothman I, Krieger JN, Muller CH. Bladder petechiae after cystoscopy and hydrodistension in men diagnosed with prostate pain. J Urol. 1998;159:83-5.

6. McKernan LC, Walsh CG, Reynolds WS, Crofford LJ, Dmochowski RR, Williams DA. Psychosocial co-morbidities in interstitial cystitis/bladder pain syndrome (IC/BPS): a systematic review. Neurourol Urodyn. 2018;37:926-41.

7. Watkins KE, Eberhart N, Hilton L, Suttorp MJ, Hepner KA, Clemens JQ, Berry $\mathrm{SH}$. Depressive disorders and panic attacks in women with bladder pain syndrome/interstitial cystitis: a population-based sample. Gen Hosp Psychiatry. 2011;33:143-9.

8. Chuang Y-C, Weng S-F, Hsu Y-W, Huang CL-C, Wu M-P. Increased risks of healthcare-seeking behaviors of anxiety, depression and insomnia among patients with bladder pain syndrome/interstitial cystitis: a nationwide population-based study. Int Urol Nephrol. 2015;47:275-81.

9. Clauw DJ, Schmidt M, Radulovic D, Singer A, Katz P, Bresette J. The relationship between fibromyalgia and interstitial cystitis. J Psychiatr Res. 1997:31:125-31.

10. Rondon L, Privat A, Daulhac L, Davin N, Mazur A, Fialip J, Eschalier A, Courteix C. Magnesium attenuates chronic hypersensitivity and spinal cord NMDA receptor phosphorylation in a rat model of diabetic neuropathic pain. J Physiol. 2010:588:4205-15.

11. Alloui A, Begon S, Chassaing C, Eschalier A, Gueux E, Rayssiguier Y, Dubray C. Does Mg2+ deficiency induce a long-term sensitization of the central nociceptive pathways? Eur J Pharmacol. 2003;469:65-9.

12. Begon S, Pickering G, Eschalier A, Mazur A, Rayssiguier Y, Dubray C. Role of spinal NMDA receptors, protein kinase $C$ and nitric oxide synthase in the hyperalgesia induced by magnesium deficiency in rats. Br J Pharmacol. 2001:134:1227-36.

13. Bagis S, Karabiber M, As I, Tamer L, Erdogan C, Atalay A. Is magnesium citrate treatment effective on pain, clinical parameters and functional status in patients with fibromyalgia? Rheumatol Int. 2013;33:167-72.

14. Wang J, Liu Y, Zhou LJ, Wu Y, Li F, Shen KF, Pang RP, Wei XH, Li YY, Liu XG. Magnesium L-threonate prevents and restores memory deficits associated 
with neuropathic pain by inhibition of TNF-alpha. Pain Physician. 2013;16: E563-75.

15. Gui WS, Wei X, Mai CL, Murugan $M$, Wu LJ, Xin WJ, Zhou LJ, Liu XG. Interleukin-1 beta overproduction is a common cause for neuropathic pain, memory deficit, and depression following peripheral nerve injury in rodents. Mol Pain. 2016;12.

16. Graziottin A, Skaper SD, Fusco M. Mast cells in chronic inflammation, pelvic pain and depression in women. Gynecol Endocrinol. 2014;30:472-7.

17. Walker AK, Kavelaars A, Heijnen C, Dantzer R. Neuroinflammation and comorbidity of pain and depression. Pharmacol Rev. 2014;66:80-101.

18. Chen JL, Zhou X, Ding HL, Zhan HL, Yang F, Li WB, Xie JC, Liu XG, Xu YC, Su MZ. Neuregulin-1-ErbB signaling promotes microglia activation contributing to mechanical allodynia of cyclophosphamide-induced cystitis. Neurourol Urodyn. 2019.

19. Liu B, Su M, Tang S, Zhou X, Zhan H, Yang F, Li W, Li T, Xie J. Spinal astrocytic activation contributes to mechanical allodynia in a rat model of cyclophosphamide-induced cystitis. Mol Pain. 2016;12.

20. Weglicki WB, Phillips TM, Freedman AM, Cassidy MM, Dickens BF. Magnesium-deficiency elevates circulating levels of inflammatory cytokines and endothelin. Mol Cell Biochem. 1992;110:169-73.

21. Winther G, Jørgensen BMP, Elfving B, Nielsen DS, Kihl P, Lund S, Sørensen $D B$, Wegener G. Dietary magnesium deficiency alters gut microbiota and leads to depressive-like behaviour. Acta neuropsychiatrica. 2015;27:168-76.

22. Slutsky I, Abumaria N, Wu L-J, Huang C, Zhang L, Li B, Zhao X, Govindarajan A, Zhao M-G, Zhuo M. Enhancement of learning and memory by elevating brain magnesium. Neuron. 2010;65:165-77.

23. Wang P, Yu X, Guan P-P, Guo J-W, Wang Y, Zhang Y, Zhao H, Wang Z-Y. Magnesium ion influx reduces neuroinflammation in $A \beta$ precursor protein/ Presenilin 1 transgenic mice by suppressing the expression of interleukin13. Cell Mol Immunol. 2017;14:451.

24. Xu T, Li D, Zhou X, Ouyang H-D, Zhou L-J, Zhou H, Zhang H-M, Wei X-H, Liu G, Liu X-G. Oral application of magnesium-l-threonate attenuates vincristineinduced allodynia and hyperalgesia by normalization of tumor necrosis factor-a/nuclear factor-kB signaling. Anesthesiology: The Journal of the American Society of Anesthesiologists. 2017;126:1151-68.

25. Mestre C, Pelissier T, Fialip J, Wilcox G, Eschalier A. A method to perform direct transcutaneous intrathecal injection in rats. J Pharmacol Toxicol Methods. 1994:32:197-200.

26. Ledeboer A, Gamanos M, Lai W, Martin D, Maier SF, Watkins LR, Quan N. Involvement of spinal cord nuclear factor $\mathrm{KB}$ activation in rat models of proinflammatory cytokine-mediated pain facilitation. Eur J Neurosci. 2005;22: 1977-86.

27. Bon K, Lichtensteiger CA, Wilson SG, Mogil JS. Characterization of cyclophosphamide cystitis, a model of visceral and referred pain, in the mouse: species and strain differences. J Urol. 2003;170:1008-12.

28. Chaplan S, Bach F, Pogrel J, Chung J, Yaksh T. Quantitative assessment of tactile allodynia in the rat paw. J Neurosci Methods. 1994:53:55-63.

29. Porsolt RD, Anton G, Blavet N, Jalfre M. Behavioural despair in rats: a new model sensitive to antidepressant treatments. Eur J Pharmacol. 1978:47:37991.

30. Yang Y, Cui Y, Sang K, Dong Y, Ni Z, Ma S, Hu H. Ketamine blocks bursting in the lateral habenula to rapidly relieve depression. Nature. 2018;554:317.

31. Abernethy MH, Fowler RT. Micellar improvement of the calmagite compleximetric measurement of magnesium in plasma. Clin Chem. 1982;28: 520-2.

32. Burnette WN. "Western blotting": electrophoretic transfer of proteins from sodium dodecyl sulfate--polyacrylamide gels to unmodified nitrocellulose and radiographic detection with antibody and radioiodinated protein A. Anal Biochem. 1981;112:195-203.

33. Liu T, Zhang T, Yu H, Shen H, Xia W. Adjudin protects against cerebral ischemia reperfusion injury by inhibition of neuroinflammation and bloodbrain barrier disruption. J Neuroinflammation. 2014;11:107.

34. Drossopoulou G, Antoniou K, Kitraki E, Papathanasiou G, Papalexi E, Dalla C, Papadopoulou-Daifoti Z. Sex differences in behavioral, neurochemical and neuroendocrine effects induced by the forced swim test in rats. Neuroscience. 2004;126:849-57.

35. Wei X-H, Zang Y, Wu C-Y, Xu J-T, Xin W-J, Liu X-G. Peri-sciatic administration of recombinant rat TNF-a induces mechanical allodynia via upregulation of TNF-a in dorsal root ganglia and in spinal dorsal horn: the role of NF-kappa B pathway. Exp Neurol. 2007;205:471-84.
36. Fasick V, Spengler RN, Samankan S, Nader ND, Ignatowski TA. The hippocampus and TNF: common links between chronic pain and depression. Neurosci Biobehav Rev. 2015;53:139-59.

37. Ren WJ, Liu Y, Zhou L, Li W, Zhong Y, Pang RP, Xin WJ, Wei XH, Wang J, Zhu $H Q$, et al. Peripheral nerve injury leads to working memory deficits and dysfunction of the hippocampus by upregulation of TNF-alpha in rodents. Neuropsychopharmacology. 2011;36:979-92.

38. Xu T, Li D, Zhou X, Ouyang HD, Zhou L, Zhou H, Zhang HM, Wei XH, Liu G, Liu XG. Oral application of magnesium-L-threonate attenuates vincristineinduced allodynia and hyperalgesia by normalization of tumor necrosis factor-alpha/nuclear factor-kappaB signaling. Anesthesiology. 2017;126: 1151-68.

39. Qu X-X, Cai J, Li M-J, Chi Y-N, Liao F-F, Liu F-Y, Wan Y, Han J-S, Xing G-G. Role of the spinal cord NR2B-containing NMDA receptors in the development of neuropathic pain. Exp Neurol. 2009;215:298-307.

40. Kim Y, Cho H-Y, Ahn YJ, Kim J, Yoon YW. Effect of NMDA NR2B antagonist on neuropathic pain in two spinal cord injury models. PAIN. 2012;153:10229.

41. Li F, Tsien JZ. Memory and the NMDA receptors. N Engl J Med. 2009;361: 302.

42. Dong J, Min S, Wei K, Li P, Cao J, Li Y. Effects of electroconvulsive therapy and propofol on spatial memory and glutamatergic system in hippocampus of depressed rats. The journal of ECT. 2010;26:126-30.

43. Yilmaz N, Demirdas A, Yilmaz M, Sutcu R, Kirbas A, Cure MC, Eren I. Effects of venlafaxine and escitalopram treatments on NMDA receptors in the rat depression model. J Membr Biol. 2011;242:145.

44. Hanno PM, Erickson D, Moldwin R, Faraday MM. Diagnosis and treatment of interstitial cystitis/bladder pain syndrome: AUA guideline amendment. J Urol. 2015;193:1545-53.

45. Hasanein P, Parviz M, Keshavarz M, Javanmardi K, Mansoori M, Soltani N. Oral magnesium administration prevents thermal hyperalgesia induced by diabetes in rats. Diabetes Res Clin Pract. 2006;73:17-22.

46. Gamelin L, Boisdron-Celle M, Delva R, Guérin-Meyer V, Ifrah N, Morel A, Gamelin E. Prevention of oxaliplatin-related neurotoxicity by calcium and magnesium infusions: a retrospective study of 161 patients receiving oxaliplatin combined with 5-Fluorouracil and leucovorin for advanced colorectal cancer. Clin Cancer Res. 2004;10:4055-61.

47. Felsby S, Nielsen J, Arendt-Nielsen L, Jensen TS. NMDA receptor blockade in chronic neuropathic pain: a comparison of ketamine and magnesium chloride. Pain. 1996:64:283-91.

48. Ishizaki K, Sasaki M, Karasawa S, Obata H, Nara T, Goto F. The effect of intrathecal magnesium sulphate on nociception in rat acute pain models. Anaesthesia. 1999:54:241-6.

49. Guo BL, Lin Y, Hu W, Zhen CX, Bao-Cheng Z, Wu HH, Kaye AD, Duan JH, Qu $Y$. Effects of systemic magnesium on post-operative analgesia: is the current evidence strong enough? Pain Physician. 2015;18:405-18.

50. Ko S-H, Lim H-R, Kim D-C, Han Y-J, Choe H, Song H-S. Magnesium sulfate does not reduce postoperative analgesic requirements. Anesthesiology: The Journal of the American Society of Anesthesiologists. 2001;95:640-6.

51. Wlaź P, Serefko A, Szopa A, Poleszak E. The effect of an acute and 7-day administration of magnesium chloride on magnesium concentration in the serum, erythrocytes, and brain of rats. Pharmacol Rep. 2016;68:289-91.

52. Singewald N, Sinner C, Hetzenauer A, Sartori SB, Murck H. Magnesiumdeficient diet alters depression-and anxiety-related behavior in mice-influence of desipramine and Hypericum perforatum extract. Neuropharmacology. 2004;47:1189-97.

53. Bardgett ME, Schultheis PJ, McGill DL, Richmond RE, Wagge JR. Magnesium deficiency impairs fear conditioning in mice. Brain Res. 2005;1038:100-6.

54. Eby GA, Eby KL. Rapid recovery from major depression using magnesium treatment. Med Hypotheses. 2006;67:362-70.

55. Eby GA III, Eby KL. Magnesium for treatment-resistant depression: a review and hypothesis. Med Hypotheses. 2010;74:649-60.

56. Hanno P, Lin A, Nordling J, Nyberg L, van Ophoven A, Ueda T, Wein A. Bladder pain syndrome international consultation on incontinence. Neurourology and Urodynamics: Official Journal of the International Continence Society. 2010;29:191-8.

57. Karin M, Delhase M: The IKB kinase (IKK) and NF-KB: key elements of proinflammatory signalling. In Seminars in immunology. Elsevier; 2000: 8598.

58. Gilmore TD. Introduction to NF-kB: players, pathways, perspectives. Oncogene. 2006;25:6680. 
59. Niederberger E, Geisslinger G. The IKK-NF-KB pathway: a source for novel molecular drug targets in pain therapy? FASEB J. 2008;22:3432-42.

60. Berthold-Losleben M, Himmerich $\mathrm{H}$. The TNF-a system: functional aspects in depression, narcolepsy and psychopharmacology. Curr Neuropharmacol. 2008;6:193-202.

61. Snow WM, Stoesz BM, Kelly DM, Albensi BC. Roles for NF-KB and gene targets of NF-KB in synaptic plasticity, memory, and navigation. Mol Neurobiol. 2014;49:757-70.

62. Ren W-J, Liu Y, Zhou L-J, Li W, Zhong Y, Pang R-P, Xin W-J, Wei X-H, Wang J, Zhu H-Q. Peripheral nerve injury leads to working memory deficits and dysfunction of the hippocampus by upregulation of TNF-a in rodents. Neuropsychopharmacology. 2011;36:979.

63. Yu X, Guan PP, Zhu D, Liang YY, Wang T, Wang ZY, Wang P. Magnesium ions inhibit the expression of tumor necrosis factor alpha and the activity of gamma-secretase in a beta-amyloid protein-dependent mechanism in APP/ PS1 transgenic mice. Front Mol Neurosci. 2018;11:172.

64. Liu YL, Zhou L, Hu NW, Xu JT, Wu CY, Zhang T, Li YY, Liu XG. Tumor necrosis factor-alpha induces long-term potentiation of C-fiber evoked field potentials in spinal dorsal horn in rats with nerve injury: the role of NFkappa B, JNK and P38 MAPK. Neuropharmacology. 2007;52:708-15.

65. Zhuo M. Plasticity of NMDA receptor NR2B subunit in memory and chronic pain. Molecular brain. 2009;2:4.

66. Locksley RM, Killeen N, Lenardo MJ. The TNF and TNF receptor superfamilies: integrating mammalian biology. Cell. 2001;104:487-501.

67. Dinarello CA. Biology of interleukin 1. FASEB J. 1988;2:108-15.

\section{Publisher's Note}

Springer Nature remains neutral with regard to jurisdictional claims in published maps and institutional affiliations.

Ready to submit your research? Choose BMC and benefit from:

- fast, convenient online submission

- thorough peer review by experienced researchers in your field

- rapid publication on acceptance

- support for research data, including large and complex data types

- gold Open Access which fosters wider collaboration and increased citations

- maximum visibility for your research: over $100 \mathrm{M}$ website views per year

At $\mathrm{BMC}$, research is always in progress.

Learn more biomedcentral.com/submissions 